Review

\title{
Dendritic Polymers as Promising Additives for the Manufacturing of Hybrid Organoceramic Nanocomposites with Ameliorated Properties Suitable for an Extensive Diversity of Applications
}

\author{
Marilina Douloudi ${ }^{1}{ }^{*}$, Eleni Nikoli ${ }^{1}$, Theodora Katsika ${ }^{1}$, Michalis Vardavoulias ${ }^{2}$ and Michael Arkas ${ }^{1, * \mathbb{D}}$ \\ 1 Institute of Nanoscience Nanotechnology, NCSR “Demokritos”, Patriarchou Gregoriou Street, \\ 15310 Athens, Greece; h.nikoli@inn.demokritos.gr (E.N.); theodorakatsika@gmail.com (T.K.) \\ 2 PYROGENESIS S.A., Technological Park 1, Athinon Avenue, 19500 Attica, Greece; \\ mvardavoulias@pyrogenesis-sa.gr \\ * Correspondence: marilina.douloudi@gmail.com (M.D.); m.arkas@inn.demokritos.com (M.A.); \\ Tel.: +30-210-650-3669 (M.A.)
}

check for

Citation: Douloudi, M.; Nikoli, E.; Katsika, T.; Vardavoulias, M.; Arkas, M. Dendritic Polymers as Promising Additives for the Manufacturing of Hybrid Organoceramic

Nanocomposites with Ameliorated Properties Suitable for an Extensive Diversity of Applications. Nanomaterials 2021, 11, 19. https: / /dx.doi.org/10.3390/nano 11010019

Received: 9 November 2020 Accepted: 20 December 2020 Published: 24 December 2020

Publisher's Note: MDPI stays neutral with regard to jurisdictional claims in published maps and institutional affiliations.

Copyright: () 2020 by the authors. Licensee MDPI, Basel, Switzerland. This article is an open access article distributed under the terms and conditions of the Creative Commons Attribution (CC BY) license (https: / / creativecommons.org/ licenses/by/4.0/).

\begin{abstract}
As the field of nanoscience is rapidly evolving, interest in novel, upgraded nanomaterials with combinatory features is also inevitably increasing. Hybrid composites, offer simple, budgetconscious and environmental-friendly solutions that can cater multiple needs at the same time and be applicable in many nanotechnology-related and interdisciplinary studies. The physicochemical idiocrasies of dendritic polymers have inspired their implementation as sorbents, active ingredient carriers and templates for complex composites. Ceramics are distinguished for their mechanical superiority and absorption potential that render them ideal substrates for separation and catalysis technologies. The integration of dendritic compounds to these inorganic hosts can be achieved through chemical attachment of the organic moiety onto functionalized surfaces, impregnation and absorption inside the pores, conventional sol-gel reactions or via biomimetic mediation of dendritic matrices, inducing the formation of usually spherical hybrid nanoparticles. Alternatively, dendritic polymers can propagate from ceramic scaffolds. All these variants are covered in detail. Optimization techniques as well as established and prospected applications are also presented.
\end{abstract}

Keywords: dendritic polymers; ceramic compounds; biomimetic; nanomaterials; dendrimers; hyperbranched polymers; silica composites; hybrid materials

\section{Introduction}

With the advent of nanotechnology and the introduction of nanoscale matter, revolutionary progress was observed in the field of materials science. The synthesis of nanoscale analogues to conventional implements with enhanced properties and a broad spectrum of applications became a routine process. Nanocomposites confirmed the hypothesis that size and shape play a pivotal role in the determination of their exquisite physical and chemical profile. The establishment of superiority over conventional microcomposites was an expected consequence. The exceptionality of these materials originates from their multilayer, core-shell-surface architecture. Depending on their core substance, they can be classified into three key categories: ceramic nanocomposites, metal nanocomposites and polymeric nanocomposites [1-3].

Ceramic materials are considered as an emerging trend of recent decades due to their mixed and flexible features, their porous, small-size structure and their broad spectrum of applications. They can appear in various forms, with the most prominent ones being ceramic membranes, ceramic nanostructures and biogenic ceramics, each form possessing exceptional uses and serving different purposes. Their capability to adopt controlled and diverse combined conformations through easily accessible, low-cost, ambient temperature 
preparation methods render them excellent candidates for the production of hybrids with optimized properties such as core-shell nanoparticles. They also constitute excellent alternatives in order to avoid the undesirable defects of their elementary equivalents, for instance toxicity, instability and high solubility [4-7].

Among the numerous properties of ceramic membranes, the most distinguished are mechanical tolerance, chemical inertia, thermal stability, damage impedance, energy conservation, high hydrophobicity, satisfactory flux at low pressures and an excessive working lifetime [6-8]. All these characteristics contribute to the suitability and expanded applicability of these membranes in various fields such as gas separation [9-11] and filtration technology $[7,8]$, water decontamination processes, water and wastewater treatment, desalination [12-16] and catalysis [11,17]. Another advantage of ceramic membranes is their employment in both microfiltration (MF) and ultrafiltration (UF) processes and less frequently in nanofiltration (NF) and reverse-osmosis (RO) [18]. Specifically, for water and wastewater purification, depending on the targeted configuration (flat-sheet or tubular) and the overall properties of the fabricated membrane, the preferred ceramic materials used are alumina, titania, zirconia and silica. Still, the non-specialized nature resulting primarily from their inability to selectively extract ultra-low-sized, "mobile" contaminants and to achieve accurately desired pore size distribution, remains one of their major drawbacks $[6,19]$.

Common problems of unprocessed ceramics such as brittle fracture, poor toughness and strength degeneration highlight the need to introduce secondary components to these materials in order to reach nanoscale ceramic products with upgraded properties. Alumina, titania, zirconia, silica and hydroxyapatite are again useful candidates for the construction of ceramic nanoparticles [20]. These nanomaterials are unique in terms of biocompatibility. Thanks to their surface modification, encapsulation and interaction with biological molecules, such as proteins, lipids and antibodies, they serve as novel diagnostic and therapeutic tools. Some examples include drug-delivery vehicles, biomedical imaging and photodynamic and photothermal therapy [21-25]. In addition, advantages linked to biocompatibility, such as increased dissolution [26], resistance to microbes, stable porosity and high selectivity, along with the facility of synthesis procedures without requirement of toxic substances and extreme conditions, make nano-ceramics the epicenter of pharmaceutical research. They combine safety with the ease of administration and controlled drug availability $[20,27,28]$. For example, the photooxidative and cytotoxic features of titania can be efficiently manipulated for the fabrication of thermally stable anatase nanoparticles. Therefore, they can be employed as excipients and in the context of photodynamic therapy for the selective treatment of several types of tumors. On the other hand, silica mesoporous nanoparticles can be readily functionalized with proteins and radioisotopes (e.g., radioiodine) to facilitate cancer detection and subsequent radiotherapy [2,3]. Similar forms can also be combined with titania analogues and yield core-shell nanomaterials with advanced catalytic and absorbing performance, as well as anti-pollutant properties [29].

Another category, bioceramics, is considered a convenient type of biomaterial in terms of applicability in biomedical engineering fields. Their biological importance stems from their surface similarities with living tissues and molecules with osseous origin, facilitating therefore their interaction with bones and teeth and thus their involvement in orthopedic therapy and tissue engineering [30-34]. To date, modern bioceramic products replace first-generation inert predecessors claiming the overthrow of conventional tissue damage treatment regimes, since they provide novel therapeutic approaches that rely on tissue repair and replacement in parallel and less on simple substitution. Second generation bioceramics include varieties of different crystallization degrees. They are characterized by high bioactivity, biodegradability and resorbability and are ideal for repairing purposes where a strong and controlled bond with the implant is required. These materials may be based on apatite sources (hydroxyapatite, calcium phosphate mixtures, bone cements based on calcium salts) that function as bone imitators against bone loss or as surface coatings for better bone deposition rates. Alternatively, they may contain a glass source (bioglasses, 
glass-ceramics) that stimulate bone growth processes by interacting with body fluids or by filling bone cavities. Likewise, third generation counterparts introduce a porous framework for the construction of scaffolds with an adjusted size and shape to accommodate specific molecular components [31,34]. Silica-based mesoporous structures and organic/inorganic hybrid composites intervene in differentiation pathways of mesenchymal cells and regulate osteogenesis and thus promote bone regeneration by exposing active molecules, such as growth factors, hormones and cells at the site of damage [30,31,34].

There is a constantly increasing interest towards the construction of new embodiments that are inspired by living systems, mimicking natural molecules and recapitulating key cellular and molecular processes that have prompted nanotechnologists to incorporate molecules bearing a dendroid architecture into their constructs. Dendritic polymers are ubiquitous materials, graced by exceptional physicochemical properties, well-defined highly branched discoid or spherical shapes and an adjustable surface area. They constitute the fourth major class of polymeric architecture and are classified as (a) monodispersed symmetric dendrimers named after the Greek word $\delta \varepsilon \dot{\varepsilon} \delta \rho o$ for tree because of their structural resemblance; (b) asymmetric species, called hyperbranched polymers; (c) fragments of both categories defined as dendrons; and (d) dendrigrafts, which are combinations of conventional (usually linear) polymers with dendritic patterns $[35,36]$. Their uniqueness emanates from their separate structural units (Figure 1): the core which is the substrate of the radial functionalization. The interior, where the "branches" reside, create a wellsuited environment for the encapsulation of guest elements. The exterior part, forming a peripheral surface, functions as an active nano-scaffold and interacts with the nearby functional groups and environmental stimuli. Some of the most established dendrimers are diaminobutane poly(propylene imine) DAB/PPI and poly(amidoamine) PAMAM (Figure 2), while their common non-symmetric hyperbranched relatives include polyglycerol PG and poly(ethylene imine) PEI (Figure 3) [37-40]. Dendritic polymer's biomimetic behavior favors their applicability in clinical fields [41,42] as drug carriers, targeted and controlled delivery vehicles [43-47] for anticancer therapeutics [48], in photodynamic therapy [49], imaging [50], diagnostics [51,52] as sensors, gene transfer agents or as artificial molecules per se $[30,35]$. Additional applications are encountered in the fields of separation systems [36,37], chromatography, membranes, hydrogels [38-44], solvent extraction [45] and color chemistry such as dyes [46].

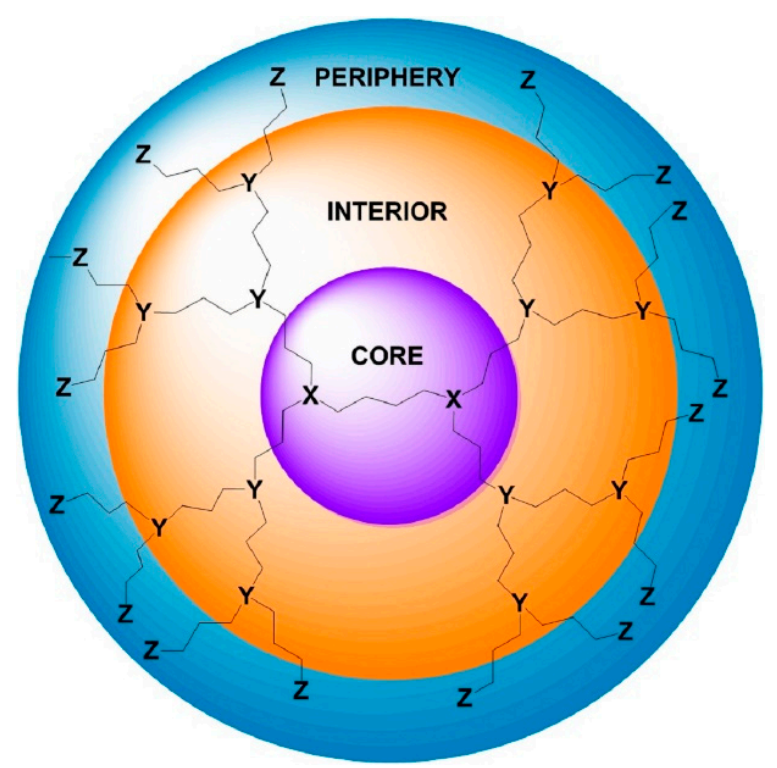

Figure 1. Schematic representation of the three structural parts of a dendritic polymer. 


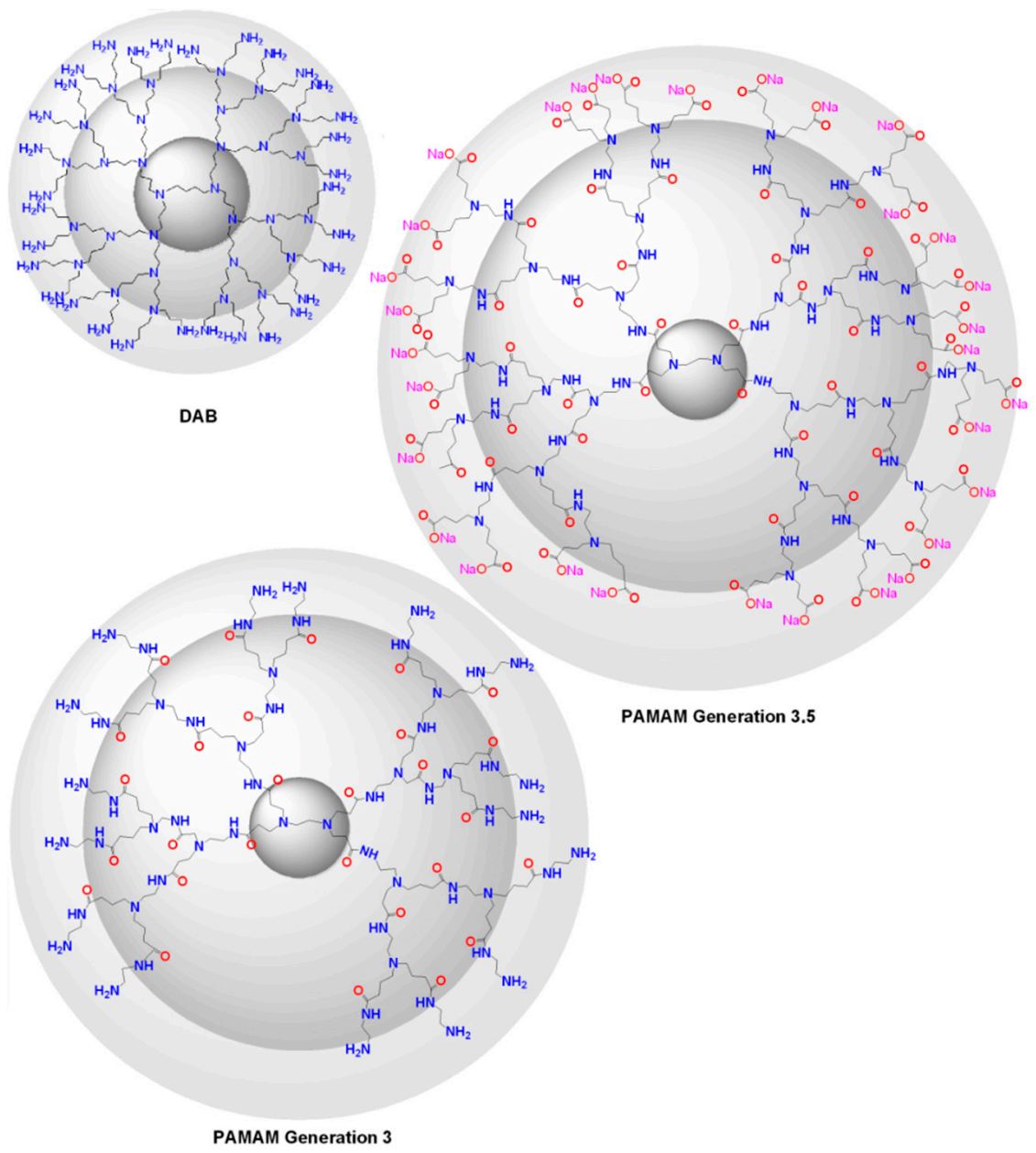

Figure 2. Chemical structures of Diaminobutanepoly(propylene imine) DAB (PPI), and Poly(amido amine) PAMAM, 3rd and 3.5rd generations.

Undoubtedly, the inauguration of interventions in the nano-scale gave the opportunity to access new conformations, synthetic or semi-synthetic, of augmented functionality, tractable structure and enhanced multi-functionality, compared to their raw counterparts. Still, the margins for improvement of nanosynthetic constructs will remain large, as long as there are unexplored aspects of different combinations of distinctive precursors. The fabrication of novel, tailor-made hybrid products profiting from combinatorial properties of suitably functionalized dendritic polymers and ceramic compounds represent powerful tool of the utmost importance. The resulting blends have the potential to substitute their unilateral sources, by considerably eliminating most of their inherent defects and benefiting from their individual assets. An inorganic/organic (ceramic/dendrimer) combination for instance can incorporate stabilizing and guest-host characteristics of the polymer matrices, in parallel with the mechanical superiority provided by the ceramic substrate [53]. The yielding organoceramics possess a confirmed potential for a multiplicity of applications, among them the most outstanding include catalysis [29,54,55], water treatment [56-59] and magnetoceramics [60]. An overview of the prevailing methods used for the synthesis of organoceramic materials will be presented in the framework of this review, along with a summary of potential barriers encountered and the proposed solutions for each given case. The most important applications of these materials will be also thoroughly outlined with a final note concerning the outlooks for the future. 

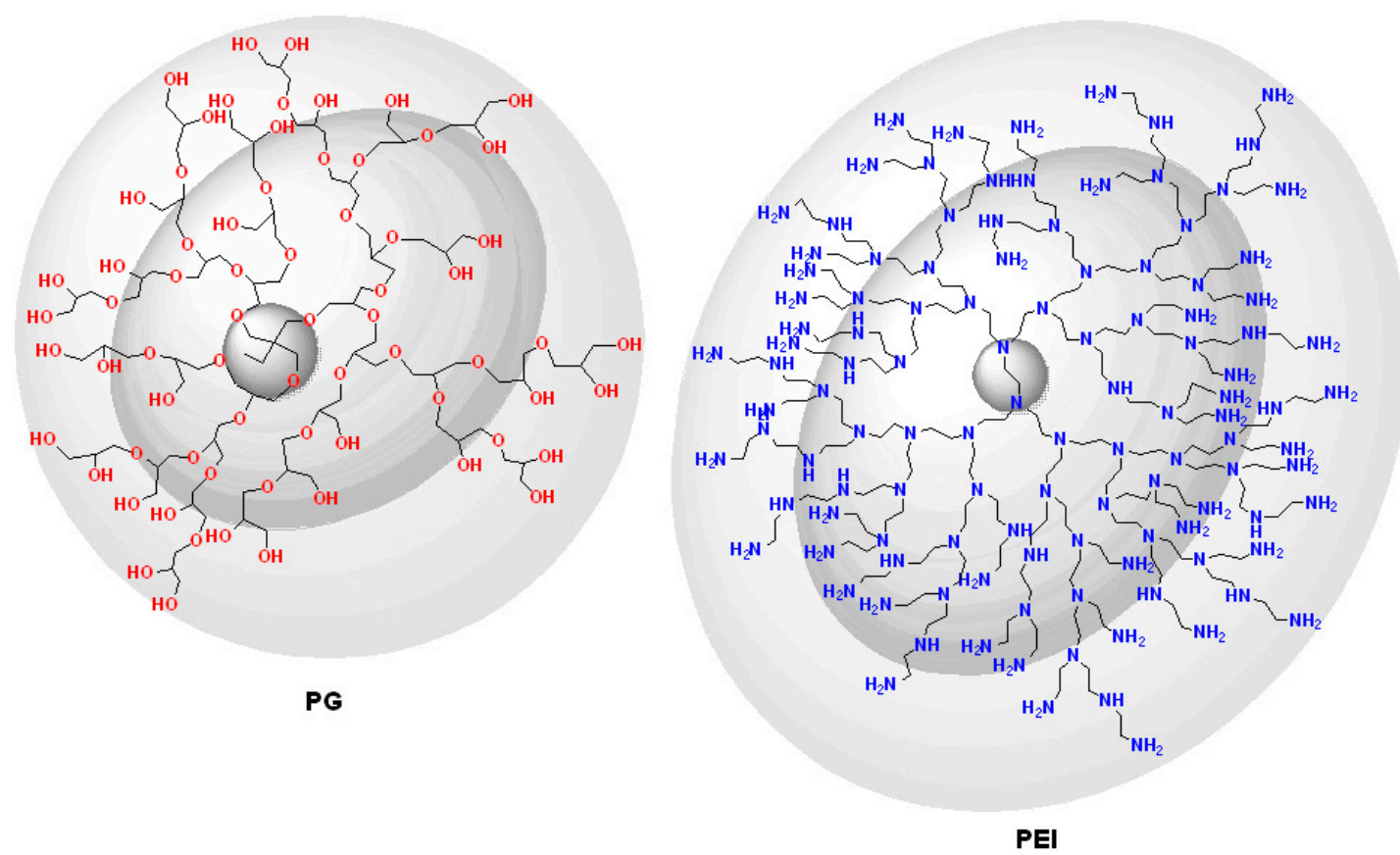

Figure 3. Chemical structures of hyperbranched polyglycerol (PG), and hyperbranched poly(ethylene imine) (PEI).

\section{Methods of Preparation}

\subsection{Simple Coating by Absorption of Dendritic Additives into the Pores of the Ceramic}

One of the easiest and fastest methods to obtain hybrids that follow a dendritic/ceramic pattern, is the direct immersion of the inorganic support possessing suitable porosity into a solution of the selected polymer [61]. In this manner, complex organic/inorganic formulations are attained that incorporate the functionalities of both constituents: (a) elevated and selective encapsulation properties, due to the highly accessible empty cavities formed by the branches of the dendritic compound; (b) perfect mechanical properties and absorption/filtering capacity that ceramic supports of variant porosity sizes and shapes can furnish. The most astonishing characteristic of this specific technique is the high polymer impregnation. Loading efficacy depends mostly on the structural components and the resting free surface area of the ceramic substrate, as well as the functionalized polymer compatibility, in terms of reactivity, with the given porous ceramic.

A first typical immersion of a silica monolith to a PAMAM G4 solution yielded a solid anion exchange polyelectrolyte gel for Prussian Blue (PB), iron(III) hexacyanoferrate(II), and cobalt(II) hexacyanoferrate(II) [62]. G2, G4 and G6 PAMAM with silica substrates have been employed in order to take advantage of the electrostatic attractions of positive charged amino groups and mount a second layer of DNA molecules for gene therapy applications [63]. Alternate layering of PAMAM and chondroitin sulphate onto mesoporous silica nanoparticles of an intensified negative charge due to the presence of a primary substrate of carboxylated PAMAM G1 led to ideal carriers for protracted release of doxorubicin and curcumin [64].

After initial capping of the silanol groups of the external surface by $\left(\mathrm{CH}_{3}\right)_{2} \mathrm{SiCl}_{2}$, G1-G3 PPI dendrimers peripherally modified by amidoferrocenes were incorporated by intermolecular hydrogen bonds to the pores of mesoporous MCM-41 silica affording hybrid redox-active ceramics [65]. Another distinguishing example that employs this impregnation approach concerns alumina filters of distinctive porosity directly immersed into an alkylated dendritic polymer solution under mild heating conditions. Octyl functionalized poly(ethyleneimine) (PEI), the proposed hyperbranched polymeric additive, serves as a cheap and facile-to-synthesize alternative to symmetric dendrimer "nanosponges", exhibiting equivalently excellent pollutant inclusion constants $\left(k_{\text {inclusion }}\right)$ [66]. It creates 
a highly homogenous water-insoluble coating, a thoroughly efficient depollution film. The hallmark of this technique is the attainment of a polymer impregnation percentage of up to $22 \%$. Interestingly, there is an analogy between the concentration of the dendritic polymer and its impregnation percentage into the same alumina filter, meaning that an increasing concentration $(0.2-30 \% w / w)$ of the alkylated PEI allows better impregnation percentages until a certain critical point. When this threshold is surpassed, small pores clog up and no additional polymer can be integrated. This critical point that marks the loading capacity of the specific ceramic compound depends primarily on the compositional characteristic of its pores. The efficient coverage of the ceramic pores is confirmed by the linearity of the plots correlating with the impregnation percentage/concentration ratio as a function of the surface area of the given alumina tube filter.

Another instance that adopts the elementary impregnation approach involves the fabrication of titania processed by PAMAM dendrimers adsorbed into its surface pores through a slurry mixture preparation [67]. The yielding nanocomposites benefit from the non-toxicity of the organic layer and the metal chelation properties introduced by functionalization of the periphery with hydroxy-terminal groups. Herein, only a partial, localized coating of the pores is achieved, driven by the electrostatic attractions developed between the hydroxyl groups of the dendrimer and the surface of titania (Figure 4). These intermolecular forces favor the immobilization process during which the dendritic molecules occupy a rather limited space compared to the total porous volume of pure titania. Specifically, this method can reach an impregnation level of $1 \%$ organic content by weight to the inorganic substrate. The composites withstood $2 \mathrm{~h}$ at $300^{\circ} \mathrm{C}$, exhibiting minimal mass loss of their active layer $(0.16 \%)$, proving their high thermal stability.

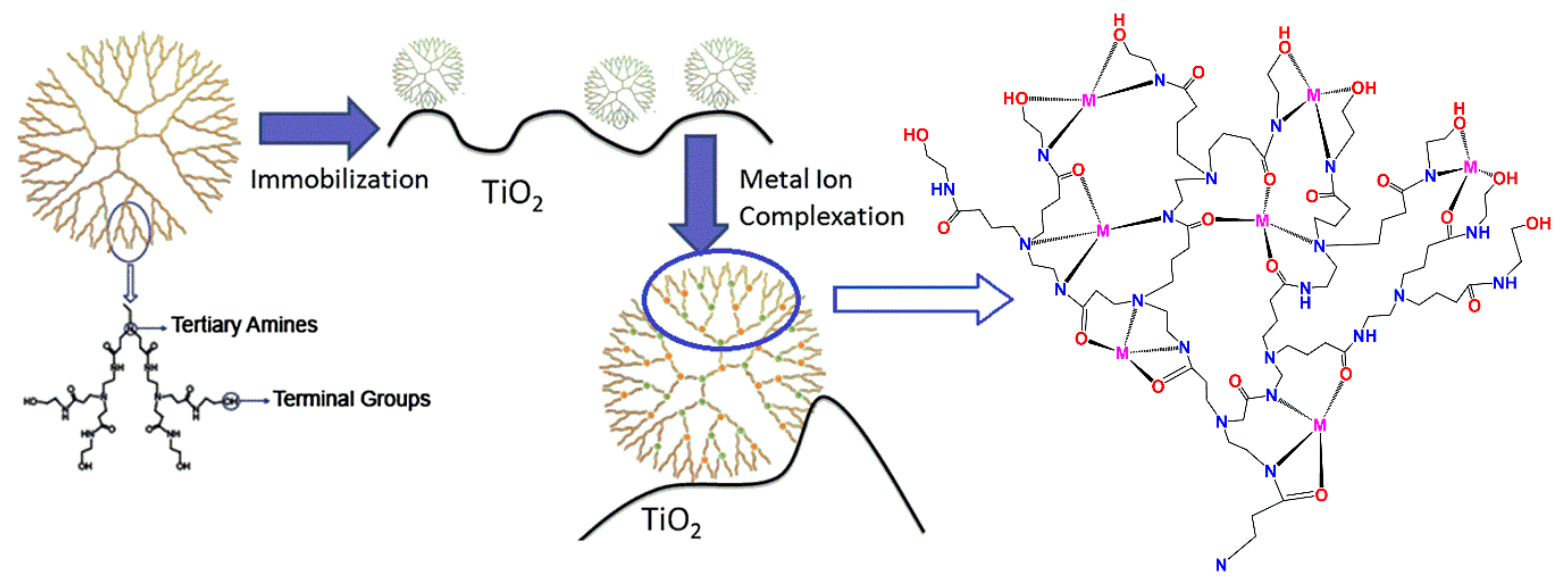

Figure 4. Schematic representation of the immobilization process of G4 dendrimers onto the surface of titania. (Reproduced with permission from [67]; Copyright Elsevier, 2013).

As expected, the impregnation rate does not depend only on the polymer concentration. The chemical nature of the selected dendrimer is a crucial factor too. The molecules are attracted to the inorganic surfaces due to intermolecular, particularly electrostatic, forces [68]. Typically, accumulation increases with increasing dendrimer generation while it is considerably larger for those with negatively charged groups (e.g., carboxylic anions) on positively charged surfaces (alumina) than that of analogues containing positive charged groups (e.g., ammonium cations) on negatively charged surfaces (silica) [69]. For this reason, the $\mathrm{pH}$ and the ionic strength of the solution exert an important influence in as much as they affect the charge of the molecules and the ceramic support [70]. Organic loading is also governed by the pore parameters of each particular ceramic [71]. This was verified by a study that evaluated the impregnation degree of silylated dendrimers and hyperbranched polymers into three ceramic filters of different origins and compared them with the homologous $\beta$-cyclodextrin derivative [58]. The resulting data demonstrated that ceramic membranes manufactured by $\mathrm{Al}_{2} \mathrm{O}_{3}, \mathrm{TiO}_{2}$ or $\mathrm{SiC}$, when immersed into a solu- 
tion of triethoxy silyl dendritic polymers of the same concentration (30\%), yielded hybrid organoceramics of different polymer contents (Figure 5). All of them, however, exhibited higher saturation limits compared to the $\beta$-cyclodextrin derivative. As was anticipated, ceramic filters with the highest porosity values $\left(\mathrm{Al}_{2} \mathrm{O}_{3}\right.$ and $\left.\mathrm{SiC}\right)$ scored the best inclusion values, while the ones with the lowest porosity values $\left(\mathrm{TiO}_{2}\right)$ presented considerably inferior impregnation properties. Pore size also regulates polymer incorporation degree considering that smaller pores allow a wider pore surface area. Therefore, the impregnation percentage of ceramics having the same porosity is determined according to the pore size. The smallest pore size, such as in alumina, in that case leads to a higher content in additives. The type of guest molecules also plays a crucial role to the extent of their incorporation, as each specific solution is characterized by different viscosity. This apparently explains the high impregnation percentages obtained by ethoxysilated polyglycerol compared to the other polymers employed in the context of this study.

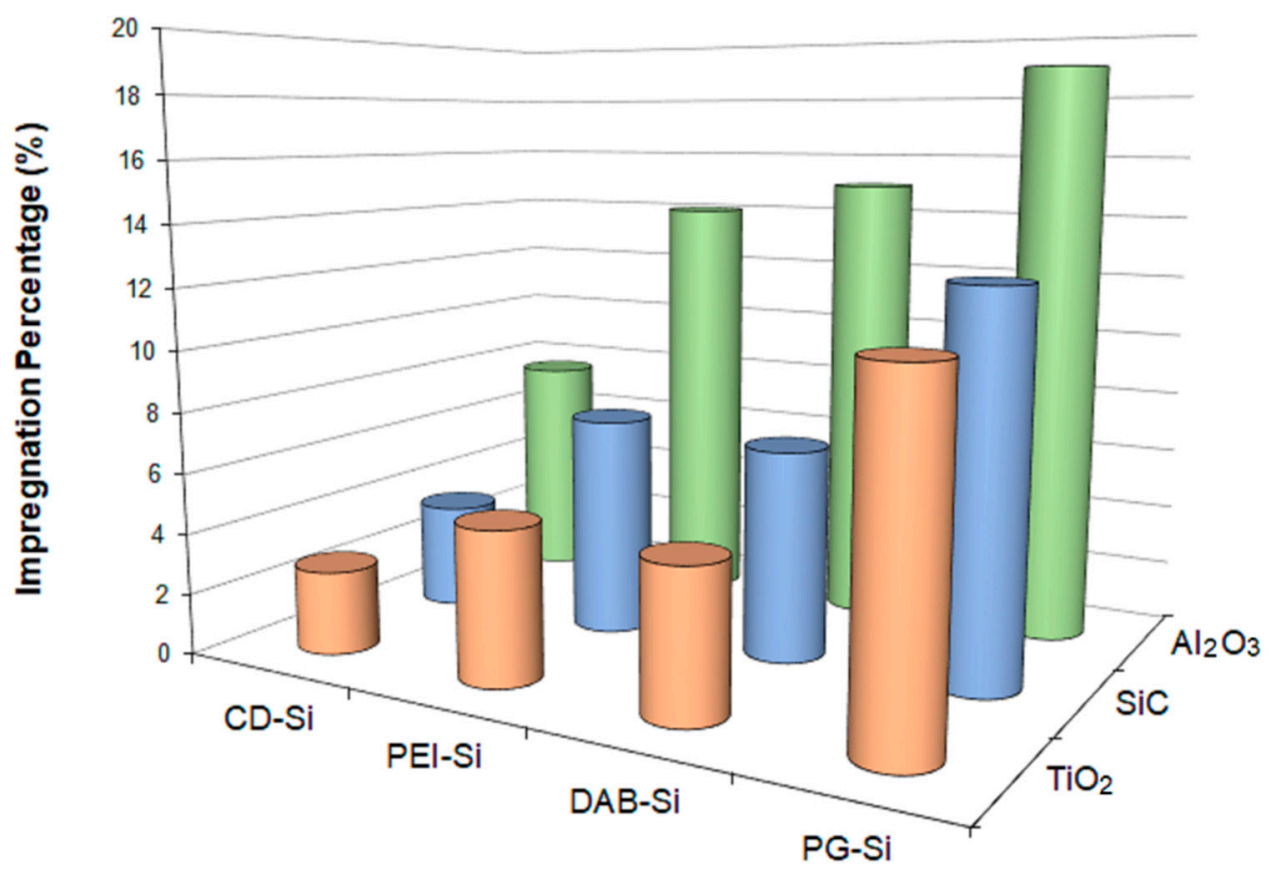

\begin{tabular}{|l|c|c|c|c|}
\cline { 2 - 5 } \multicolumn{1}{c|}{} & $\mathrm{CD}-\mathrm{Si}$ & $\mathrm{PEI}-\mathrm{Si}$ & DAB-Si & PG-Si \\
\hline$\square \mathrm{TiO}_{2}$ & 2.75 & 5.01 & 4.84 & 11.13 \\
\hline$\square \mathrm{SiC}$ & 3.5 & 7.25 & 6.9 & 12.51 \\
\hline$\square \mathrm{Al}_{2} \mathrm{O}_{3}$ & 7.63 & 14 & 15 & 18.93 \\
\hline
\end{tabular}

Figure 5. Loading percentage for three ceramic filters of different origins $\left(\mathrm{TiO}_{2}, \mathrm{SiC}_{2} \mathrm{Al}_{2} \mathrm{O}_{3}\right)$ after their immersion into $30 \%$ solutions of triethoxy silated dendritic and cyclodextrin polymers (Reproduced with permission from [59]; Copyright Elsevier, 2006).

\subsection{Attachment of Polymers with Covalent Bonds to the Surface of the Ceramic Substrate}

The performance of the nanocomposites is largely dictated by their surface features. A well-defined and fully characterized external surface leads to better prediction and management of the resulting material properties, such as active ingredient solubility/release and reactivity with the other active factors present. Chemical reactions with active groups induced on the ceramic, for instance by etching with strong acid or base are the conventional, versatile method to obtain highly specialized and flexible modified surfaces. Dendritic polymers, known for the high local concentration of exposed external surface groups, branching diversity and hence susceptibility to chemical interventions, represent unique options to afford hybrid materials with desired chemical profiles. The functionalization of dendritic polymers with groups based on silicon, has gained considerable 
interest. They offer active sites, commonly silanols, which can subsequently react with chemically relative ceramic substrates, forming stable siloxane bridges through curing processes [56,72]. Some of the most prominent advantages of these Si-heteroatom dendrimers over the conventional ones are as follows: (a) unrestrained shaping and tailoring of the dendrimer structure density with Si atoms as the branching centers of the last 2 or 3 generations; (b) efficient diffusion into the ceramic filler or membrane and improved impregnation rate. This results in lower activation energy requirements and secure reduced curing temperatures and cost effectiveness; and (c) a variety of synthetic pathways.

Production of organosilicon-based ceramics can be implemented through methods such as cross-linking, sol-gel processing, pyrolysis and ceramization. During the fabrication procedure, emphasis should be given to the specifications of the selected dendrimer, and more specifically in its molecular weight, which should be as high as possible, in its solubility into the solution of the ceramic precursor and in its stereochemical convenience to perform cross-linking. Chemical stability of the resulting hybrid material depends on the type of formed bonds. Covalent bonds are the most suitable for sustainability. By being stable they provide the option of regeneration without substantial organic material loss and therefore allow repeated use. Formation of chemical bonds between the dendritic polymer and the ceramic substrate can be established through the sol-gel reaction. The effectiveness of this method in producing organoceramics is based on the employment of appropriate functionalized silyl-reactants, particularly alkoxylates, established for their capability to undergo hydrolysis under acidic conditions [59]. Full conversion is crucial for the shaping of the final product, as heterogeneity affects negatively both the compatibility and the structure of the hybrid ceramic. Triethoxylated derivatives of dendritic molecules, for instance DAB, PEI and PG, are susceptible to rapid hydrolysis, delivering silanols, which in turn can react intramolecularly or intermolecularly with adjacent hydroxyl groups via a condensation mechanism (Figure 6a). Dendritic silanols can condensate with the hydroxyl groups of the targeted ceramic surface as well, enabling the formation of a chemically bound film (Figure 6b). Activation of the ceramic surface and formation of hydroxyl groups is a prerequisite for the reaction and can be performed by using several techniques. An interesting activation example proposed by Ottenbrite is the etching through immersion into the $1 \mathrm{M}$ $\mathrm{NaOH}$ solution for some hours, followed by extensive washing with methanol and water and drying under vacuum conditions [73]. This process combined with curing at slightly increased temperatures, successfully promoting the development of nanostructured hyperbranched PEI covalently attached to an activated ceramic filter for absorption of mono and polycyclic aromatic hydrocarbons, pesticides, trihalogen alkanes and methyl tert-butyl ethers [59]. Implementation of this exact synthetic pathway with G3 PPI dendrimer loaded with ibuprofen or levofloxacin on mesoporous silica nanoparticles afforded antimicrobial agents to be defined as nanoantibiotics [74,75]. Interference of disulfide bridges between sulfur-containing G1-G5 PPI and accordingly modified mesoporous silica nanoparticles loaded with fluorescent dyes (fluorescein disodium salt and carboxyfluorescein) generated redox-responsive stimuli-triggered release carriers [76]. The transformation of disulfides to sulfhydryl groups in the presence of a reductive reagent removes the dendrimers and permits the discharge of the active ingredients.

Antibacterial PAMAM and carbosilane dendrimers and dendrons have been grafted to silica surface too [77], either by mediation of triethoxysilylpropyl succinic anhydride silane (TESPSA) or by direct grafting, biocompatible G2 and G3 carbosilane dendrons bearing ammonium or tertiary amine groups were attached to mesoporous silica nanoparticles in order to serve as nonviral gene delivery systems [78]. Alternative carbosilanes with $\mathrm{Si}-\mathrm{Cl}$ at the focal point and peripherally modified zirconocene were used as catalysts [79]. Co-condensation of PAMAM dendron (G1.0) containing a triethoxysilyl coupling agent and tetraethoxy silane (TEOS) in different molar ratios with the addition of cetyltrimethylammonium bromide (CTAB) as pore-directing agents, yielded $\mathrm{Hg}^{2+}$ absorbing silica-gel sol-gel [80]. Non-activated mesoporous silica required reflux for $12 \mathrm{~h}$ in DMF under ni- 
trogen in order to form bonds with triethoxy-sillylated PAPAM dendrons and provides composite nanoparticles for drug delivery (curcumin) and fluorescence imaging [81].
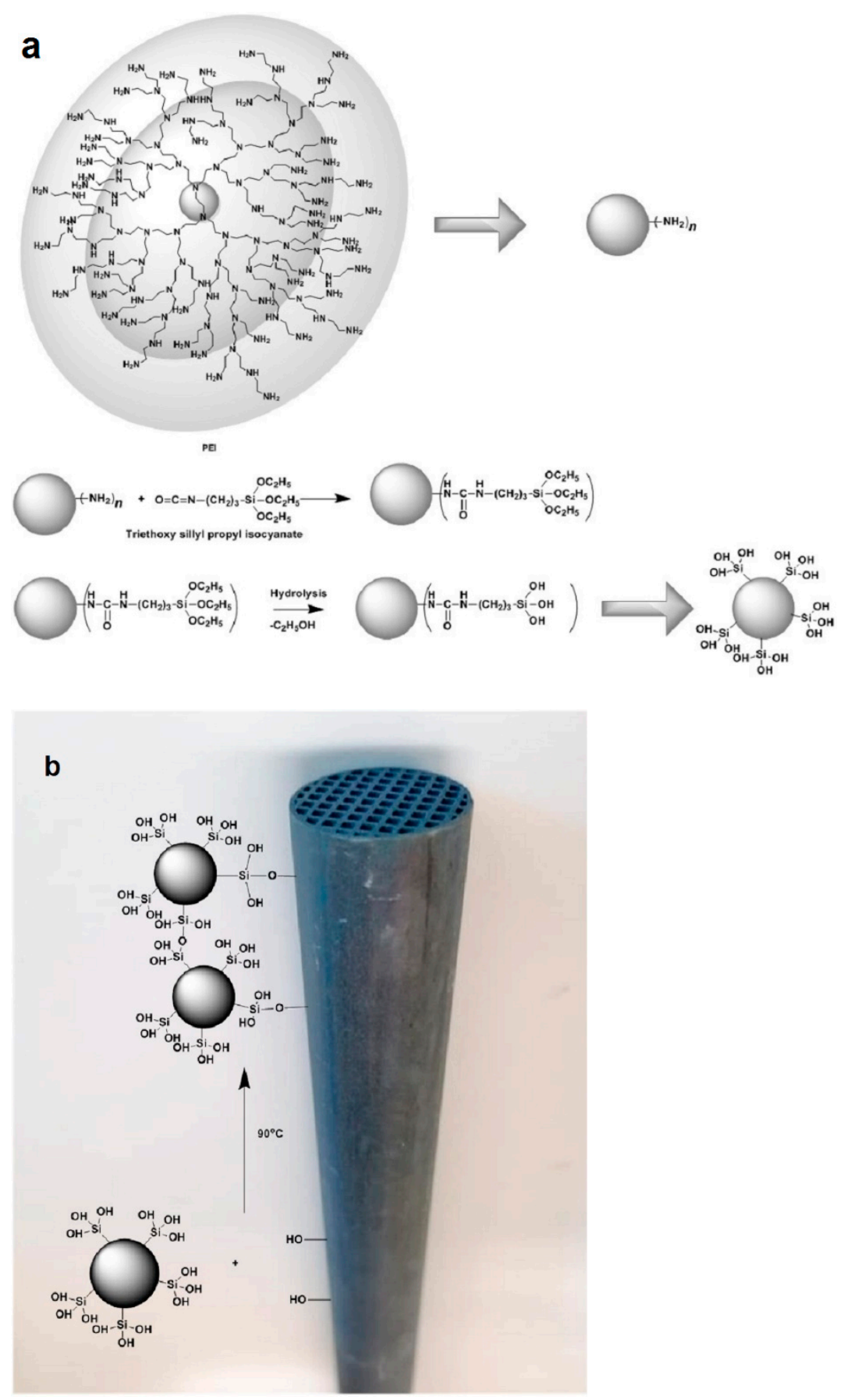

Figure 6. (a) Hydrolysis of triethoxysilyl derivatives forming silanols susceptible to polycondensation with neighboring hydroxy groups; (b) attachment of functionalized dendritic polymers on the surface of silica ceramic filters by formation of siloxane bridges (Reproduced with permission from [59]; Copyright Elsevier, 2006).

The adjustable external surface and internal cavities of dendrimers renders them extremely selective and prone to interventions aiming to enhance their chemical affinity to specific targets. The application of their derivatives that are prone for sol-gel reactions as sorbents for undesirable substances removal and analytical extractions, such as solid phase microextraction (SPME) and capillary microextraction, is common [82,83]. Deficient im- 
mobilization of the polymeric coating on the fused silica capillary is a typical shortcoming encountered in conventional SPME methods, delaying or even blocking full extraction of a wide range of analytes. Sol-gel processing, however, guarantees firm attachment, allowing for improved extraction performance and maximum use of the overall analytical potential. One of the first studies that investigated adsorptive capacity of dendritic molecules in solventless microextraction and polycondensation, introduced benzyl-terminated dendrons as a chemically stable coating on the inner walls of fused silica capillaries. Principles of sol-gel processing were exploited in order to form and maintain a strong chemical connection between the organic coating and the inorganic substrate and achieve the highest possible stability towards thermal and solvent distortions. The attachment of benzyl-terminated dendrons was accomplished by the mediation initially of 3-(triethoxysilyl)ethylamine and then methyltrimethoxysilane. The introduction of ethoxysil groups into the roots of the dendron enables sol-gel hydrolysis and polycondensation, creating thus a dendritic stationary phase bonded to the column walls, characterized by remarkable uniformity and a roughened, porous appearance (Figure 7). Various types of bifunctional poly(phosphorhydrazone) dendrons and dendrimers were likewise modified by triethoxysilyl moieties for grafting to silica and by amines for trapping $\mathrm{CO}_{2}[84]$.

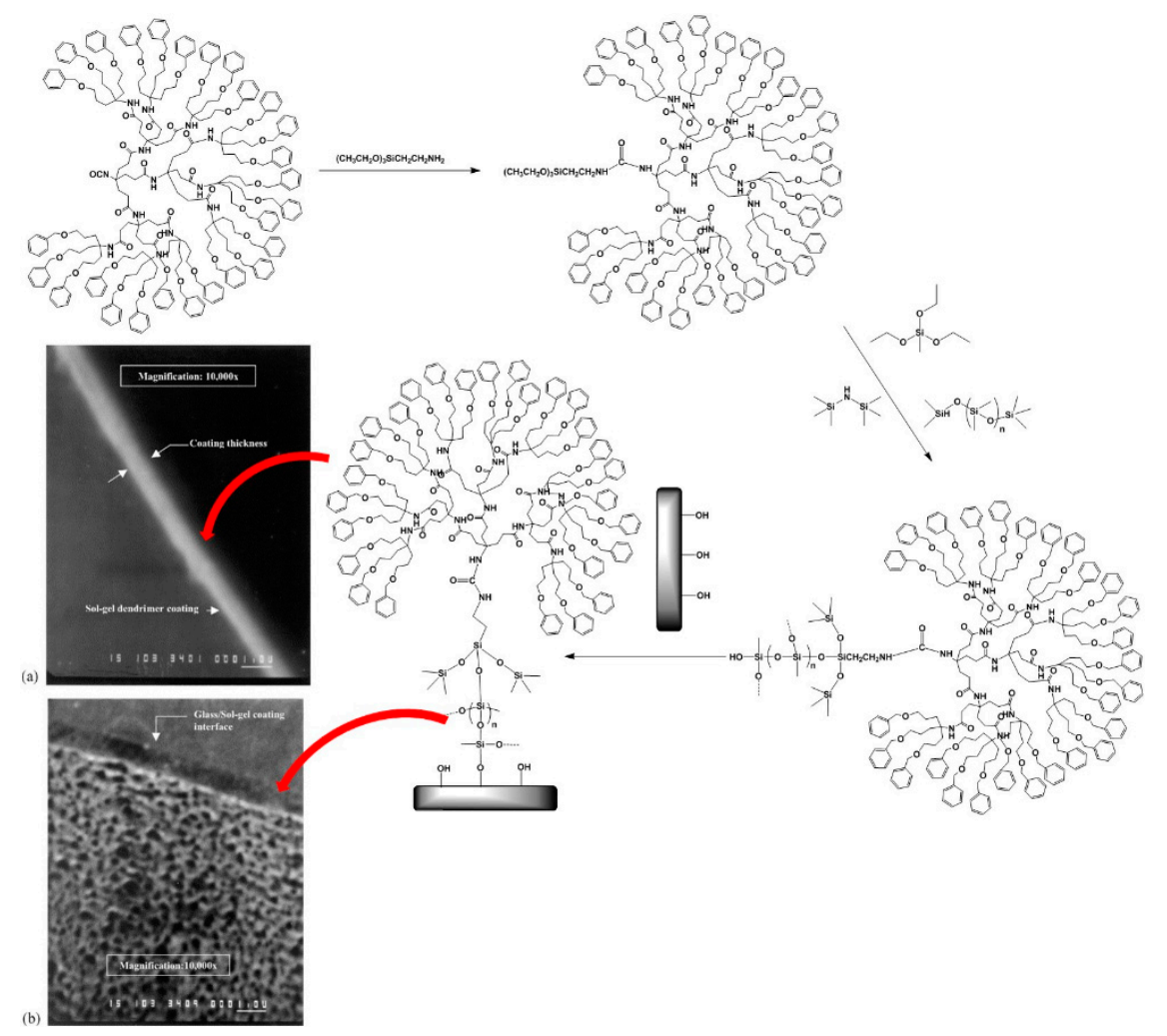

Figure 7. Synthesis of Phenyl-terminated dendrimer with triethoxysilyl root and subsequent immobilization to a fused silica capillary. SEM micrographs of coating thickness (a) $(0.5 \mu \mathrm{m})$ and roughened porous texture (b). (Reproduced with permission from [83]; Copyright Elsevier, 2004).

Another variation that involves reaction with activated rough surfaces and subsequent sol-gel siloxane bond formation, exploits the selectivity potential of hyperbranched PEI by grafting onto the surface of a magnetic porous ceramic [85]. The selected ceramic powder was composed of $\mathrm{Fe}_{3} \mathrm{O}_{4}$ and $\mathrm{SiO}_{2}$ in order to combine and inherit the magnetism of magnetite with surface adaptability and chemical stability of silica. This powder was efficiently prepared through dispersion polymerization that involves the coupling of $\gamma$ chloropropyltrimethoxysilane. The production of $\mathrm{SiO}_{2} @ \mathrm{Fe}_{3} \mathrm{O}_{4}$-PEI nanocomposites follows a simple two-step process. The magnetic porous ceramic substrate is first activated with methanesulfonic acid, promoting the creation of silanol groups. The latter then underwent 
a reaction with the corresponding analogues of hydrolized $\gamma$-chloropropyltrimethoxysilane at $80^{\circ} \mathrm{C}$ to yield a chlorine functionalization reaction. The final step includes the synthesis of the anticipating adsorptive composite by reaction of the porous magnetic ceramic compound with $10 \%$ PEI solution at $90{ }^{\circ} \mathrm{C}$ for $6 \mathrm{~h}$. In this way, magnetic porous adsorbents with an excessive separation performance and a faster adsorption equilibrium are produced (Figure 8). Another variant implementing magnetic silica $\left(\mathrm{SiO}_{2}-\mathrm{Fe}_{3} \mathrm{O}_{4}\right)$ and Pyridylphenylene dendrons adopted two approaches with 3-(iodopropyl)trimethoxysilane or (3-aminopropyl)triethoxysilane (Figure 9) in order to get efficient stabilizing hosts of $\mathrm{Pd}$ catalysts [86].
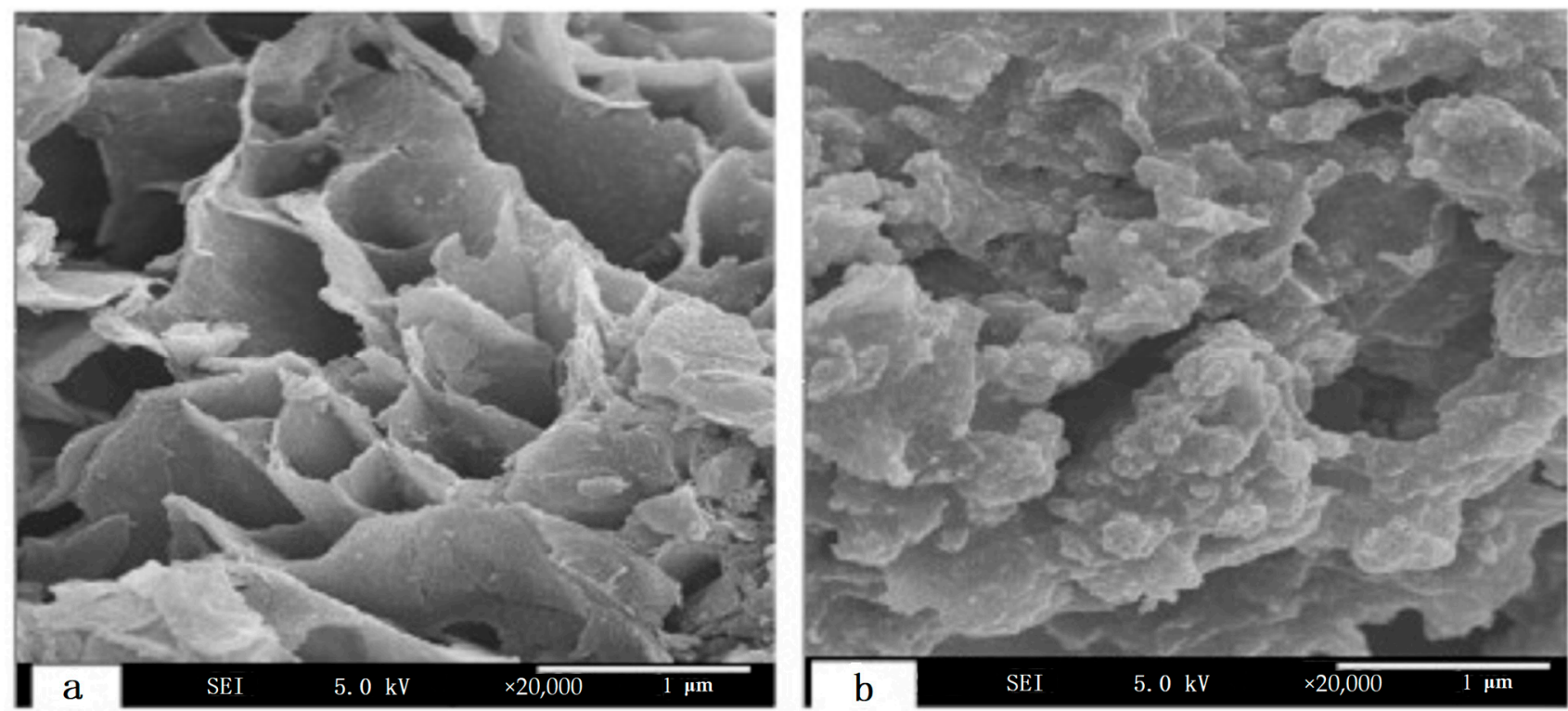

Figure 8. SEM micrographs of $\mathrm{Fe}_{3} \mathrm{O}_{4}$ and $\mathrm{SiO}_{2}$ composite magnetic powder (a) and PEI-grafted adsorbent (b). (Reproduced with permission from [85]; Copyright Elsevier, 2011).

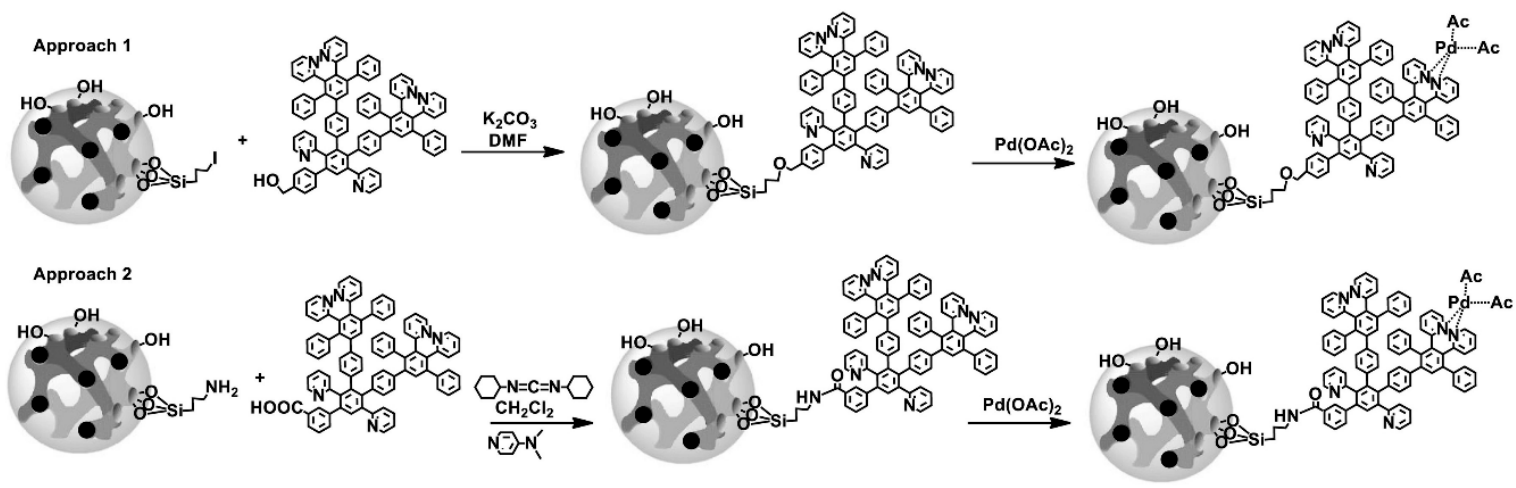

Figure 9. Attachment of Pyridylphenylene dendrons to magnetic silica with the aid of iodine (Approach 1) or amino (Approach 2) groups succeeded by the complexation with Pd acetate. (Reproduced with permission from [86]; Copyright Elsevier, 2019).

While symmetric dendrimers have been intensively studied for their catalytic properties in homogeneous catalysis, limited information is available for their contribution to the field of heterogeneous or the so-called immobilized catalysts on porous media. A very hopeful area that addresses the insufficiently selective and enantioselective behavior of heterogeneous inorganic supports in asymmetric reactions. It also incorporates the prospect of chiral dendrimers on inorganic supports as catalytic alternatives for enantiomeric reactions [87]. Specifically, the study conducted by Chung et al. describes the application of 3-glycidoxypropyl-trimethoxysilane in the development of silica-supported chiral catalysts 
based on PAMAM dendrimers (Figure 10) for the enantioselective addition of diethylzinc to benzaldehyde. The chemical grafting reaction of the $n$th PAMAM generation dendrimer derivative onto the silica substrate proceeds under the presence of methanol and reflux for $4 \mathrm{~h}$. The resulting composite can then be further treated to achieve the desired peripheral chiral functionality by reaction with $(1 R, 2 R)-(+)-1$-phenylpropylene oxide and the optional presence of a long alkyl chain spacer.

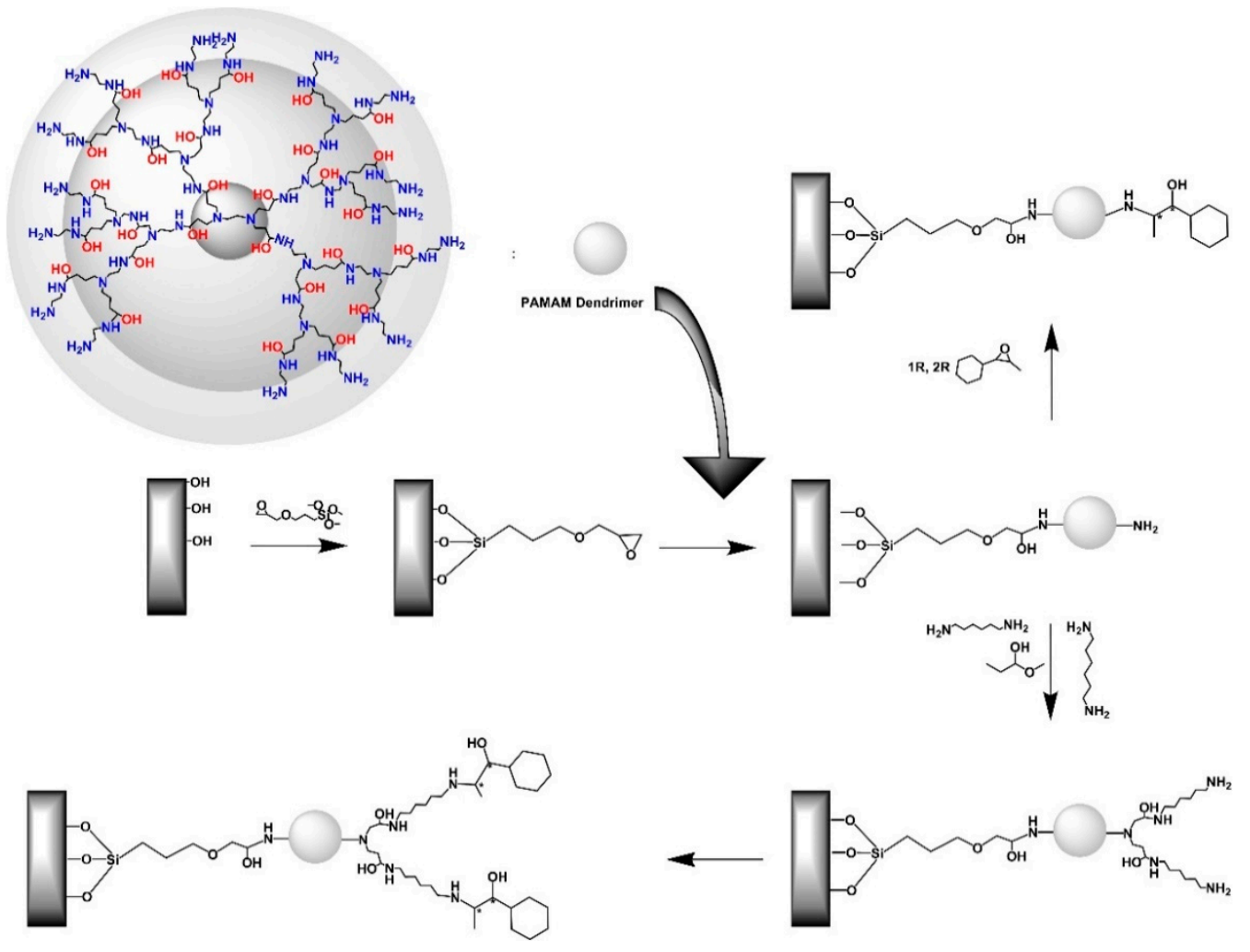

Figure 10. Synthetic path for the immobilization of PAMAM dendrimers decorated by chiral functionality onto silica substrate. (Reproduced with permission from [87]; Copyright Elsevier, 2003).

Implementation of the same concept by the aid of chloropropyl trichloro silane and polyallylamine permitted the coupling of G3 PPI to an amorphous silica gel and the posterior immobilization of palladium nanoparticles for selective hydrogenation catalysis [88]. On the other hand, aminopropyl triethoxy silane (APTES) was required in order to bind polyphosphorhydrazone (PPH) dendrimers on thermally activated silica nanoparticles [89]. Further derivatization of the remaining aldehyde groups with aminefunctionalized Poly(Ethylene (Glycol) (Figure 11a) afforded hybrid nanocarriers for silver and silver oxide colloids that exhibit antibacterial activity. Carboxy derivatized glutamic acid-based chiral dendrimers with peptide linkages coupled with APTES gave silica chiral stationary phases for use in HPLC [90], whereas the same reagent in conjunction with 1,10-carbonyldiimidazole was used for binding G1, G3, G4, G5 PAMAM. Their subsequent loading with fluorescein isothiocyanate or rhodamine $B$ isothiocyanate led to photoluminescence sensors for cyanide and copper ions, respectively [91]. Dendritic fragments bearing specialized sol-gel bonds forming groups at their focal point demonstrate another beneficial feature. They serve as convenient media to secure high local concentrations of active ingredients by protracting, for instance, the lifetime of hydrophobic species in aqueous solutions. This stabilizing aspect is confirmed in a study where PAMAM dendrons displayed a protecting effect over water-dispersible $\mathrm{TiO}_{2}$ nanocomposites. The establishment of a strong chemical Si-O-Ti bond created a screening polar shell to the solubilized metal oxide from the aqueous environment and thus hampered flocculation [92]. The formation of $\mathrm{TiO}_{2}$ nanoparticles, and the chemical attachment of PAMAM dendrons (generation 1-3) carrying 
siloxy focal points and long alkyl chains (hexyl, C6), was realized through hydrolysis of tetraisopropylorthotitanate and subsequent formation of Ti-O-Si bonds. Both reactions proceeded simultaneously in the same pot, mixing various ratios of the titania precursor and the functionalized dendron in 1-propanol solution at $0{ }^{\circ} \mathrm{C}$ and then pouring the mixture in water. The final configuration of dendron-protected titania (Figure 11b) was defined by the metal ion/dendron ratio and the generation of the latter, while its size was only generation-dependent. This functionalization of titania nanoparticles enhanced their photocatalytic activity towards 2,4-dichlorophenoxyacetic acid degradation.

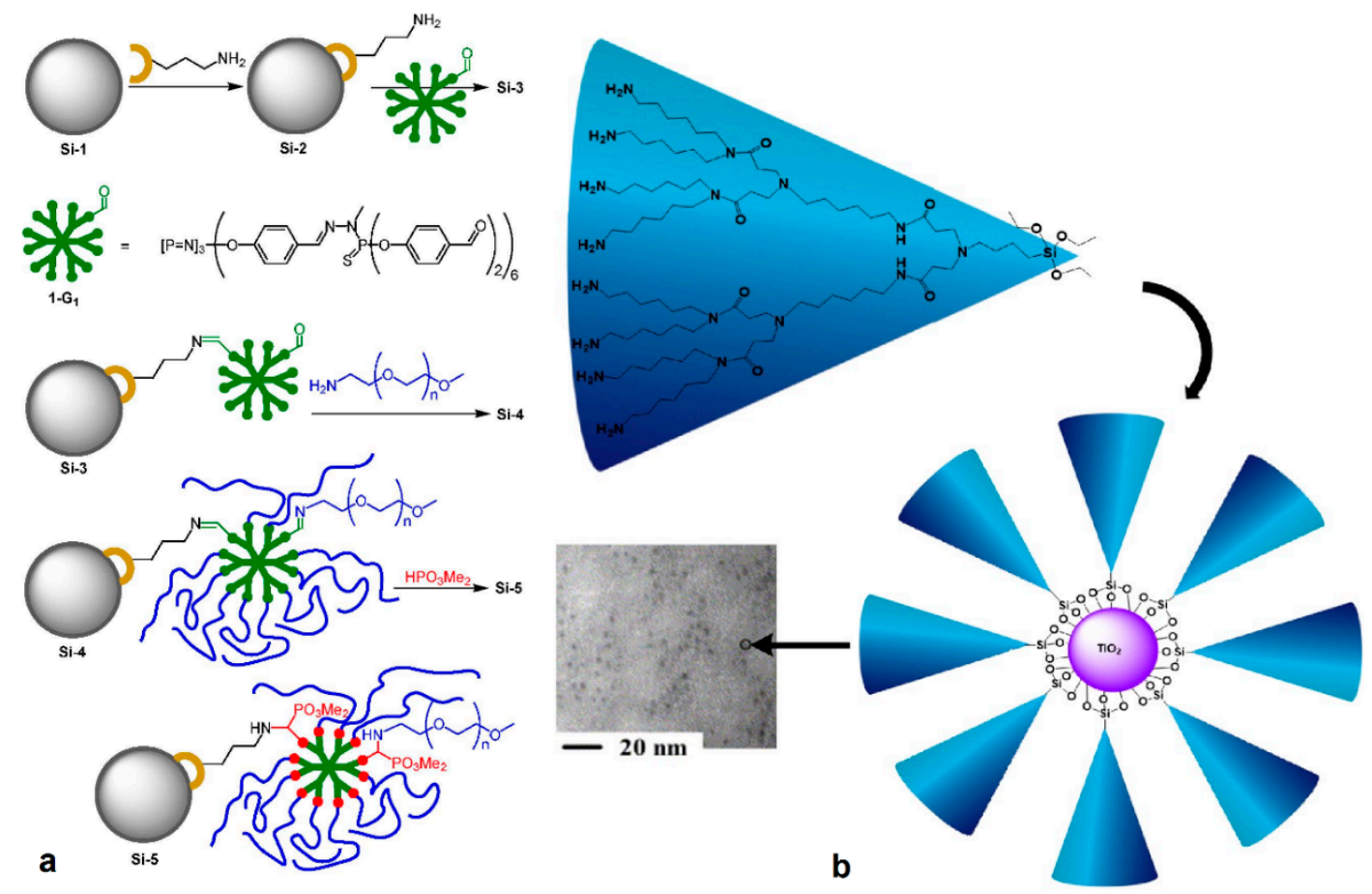

Figure 11. (a) Synthetic path for grafting polyphosphorhydrazone dendrimers onto functionalized silica and following modification of its periphery with Poly(EthyleneGlycol) chains. (Reproduced with permission from [89]; Copyright Royal Society of Chemistry, 2013). (b) Pathway for the clipping of the PAMAM dendron protective layer to titania photocatalytic nanoparticles and SEM micrograph of the complexes (Reproduced with permission from [92]; Copyright Elsevier, 2005).

Some other reactive groups may be introduced to ceramic surfaces. Such organosilicates are even commercially available. Silica gels bearing isocyanate or maleimide groups were successfully used for binding PAMAM dendrimers and derivatives thereof [93] for $\mathrm{Cu}^{2+}$ absorption studies [94], whereas 3-(1-Piperazino)propyl-functionalized gels presented an ideal substrate to immobilize melamine-based dendrons and were implemented for pesticide (atrazine) containment [95].

\subsection{Direct Growth of Dendritic Polymers on the Surface of Ceramics}

Another strategy for the decoration of the ceramic surface by dendritic sequences is the direct propagation of dendrons on their surface through conventional divergent pathways. This solid-phase synthesis technique is a quick and simple alternative for the preparation of hybrid "dendro-ceramers". Most of the studies employing this direct growth method are based on silica gels. Nevertheless, the main stages formulating the synthesis schemes that ultimately lead to the product of interest remain the same, both for gels and ceramics: (a) surface activation reaction; (b) dendron core binding; and (c) outspread of the branches. 
The grafting of PAMAM dendrimers into the silica surface can be easily achieved by performing three successive reaction steps $[85,96]$. At the outset, the amino core of PAMAM polymers is introduced to the activated silica surface through the interaction between the silanol surface groups and 3-aminopropyltriethoxylsilane (APES). This reaction is carried out at $110^{\circ} \mathrm{C}$ in toluene for $48 \mathrm{~h}$. PAMAM sprouts then proliferate by repetitive additions of a branching unit. Evolution of dendrons on silica surface can be accomplished through a series of successive alternate Michael addition and amidation reactions. Michael addition of methyl acrylate (MA) to the terminal amine generates amino propionate esters. Subsequent amidation with ethylene diamine (EDA) results in the first generation dendron. Repetitive Michael additions and amidations afford higher generations [97]. This primary PAMAM coating of silica exhibited high complexation affinity for $\mathrm{Zn}$ (Figure 12a) and equally excellent metal ion absorption efficiency for $\mathrm{Zn}^{2+}$ [98], $\mathrm{Mn}^{2+}$ [99], Ni ${ }^{2+}$ [100], $\mathrm{Co}^{2+}[98,101], \mathrm{Cd}^{2+}[102,103], \mathrm{Fe}^{3+}[103,104]$ (Figure 12b), $\mathrm{Pb}^{2+}$ [105] and U(IV) [106]. Employing exactly the same pattern, Alper et al. grew G4 PAMAM dendrons inside the channels of pore-expanded periodic mesoporous silica [107]. Mesoporous silica particles incorporating PAPAM were used as well for generation-dependent size exclusion chromatography columns [108]. Further treatment of PAMAM dendron external groups with salicylaldehyde [109] enables the effective removal of $\mathrm{Hg}^{2+}$ from water, whereas processing by methyl isothiocyanate permits absorption of both $\mathrm{Hg}^{2+}$ [110], (Figure 13a,b) and $\mathrm{Ag}^{+}$[111] (Figure 13c) and also from ethanol [112].

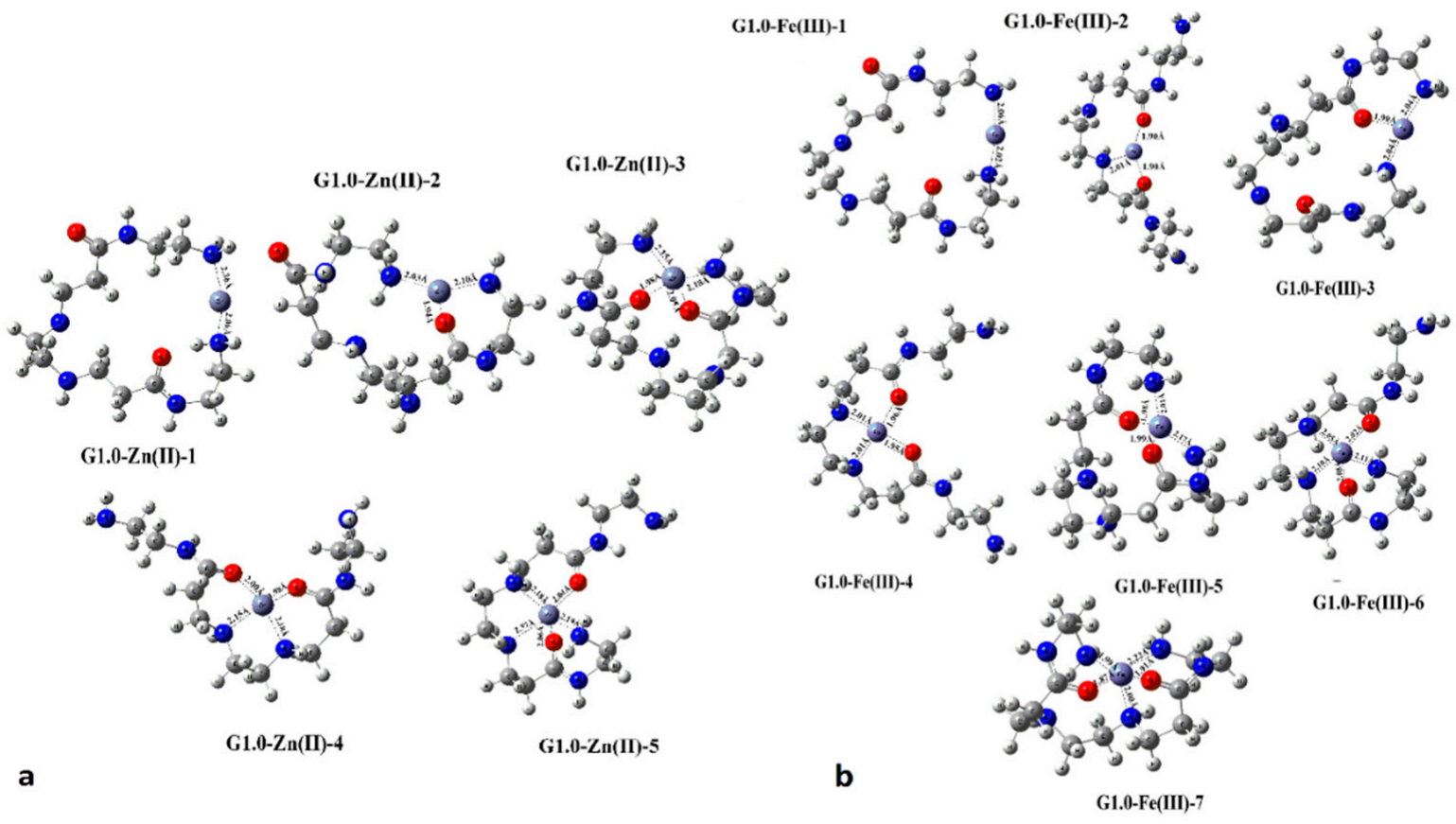

Figure 12. Optimized coordination structures of PAMAM G1.0 with (a) Zn(II) (Reproduced with permission from [98]; Copyright Elsevier, 2020) and (b) Fe(III) (Reproduced with permission from [103]; Copyright Elsevier, 2018).

Addition of n-octadecylisocyanate [97] leads to the introduction of long aliphatic chains to the periphery of the dendrons (Figure 14). In this way, production of amphiphilic silica bearing a hydrophilic dendritic core combined with a hydrophobic surface is obtained and is designed to deal with lipophilic pollutant encapsulation issues. 


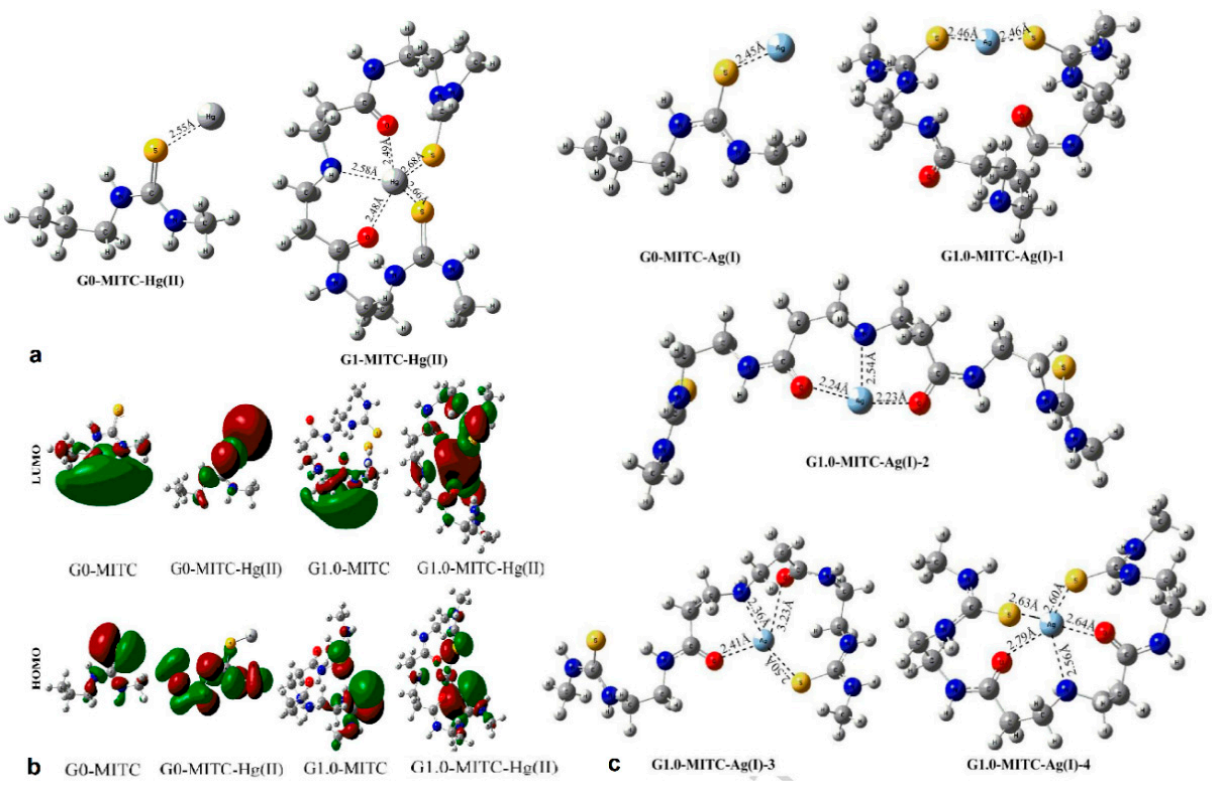

Figure 13. Optimized geometries (a) and contour plots (b) of the highest occupied molecular orbitals HOMOs (red) and lowest unoccupied molecular orbitals LUMOs (green), of $\mathrm{Hg}^{2+}$ complexes with methylisothiocyanated (MITC) G0-PAMAM and G1.0-PAMAM. (Reproduced with permission from [110]; Copyright American Chemical Society, 2016); (c) Optimized geometries of the respective silver complexes (Reproduced with permission from [111]; Copyright Elsevier, 2018).

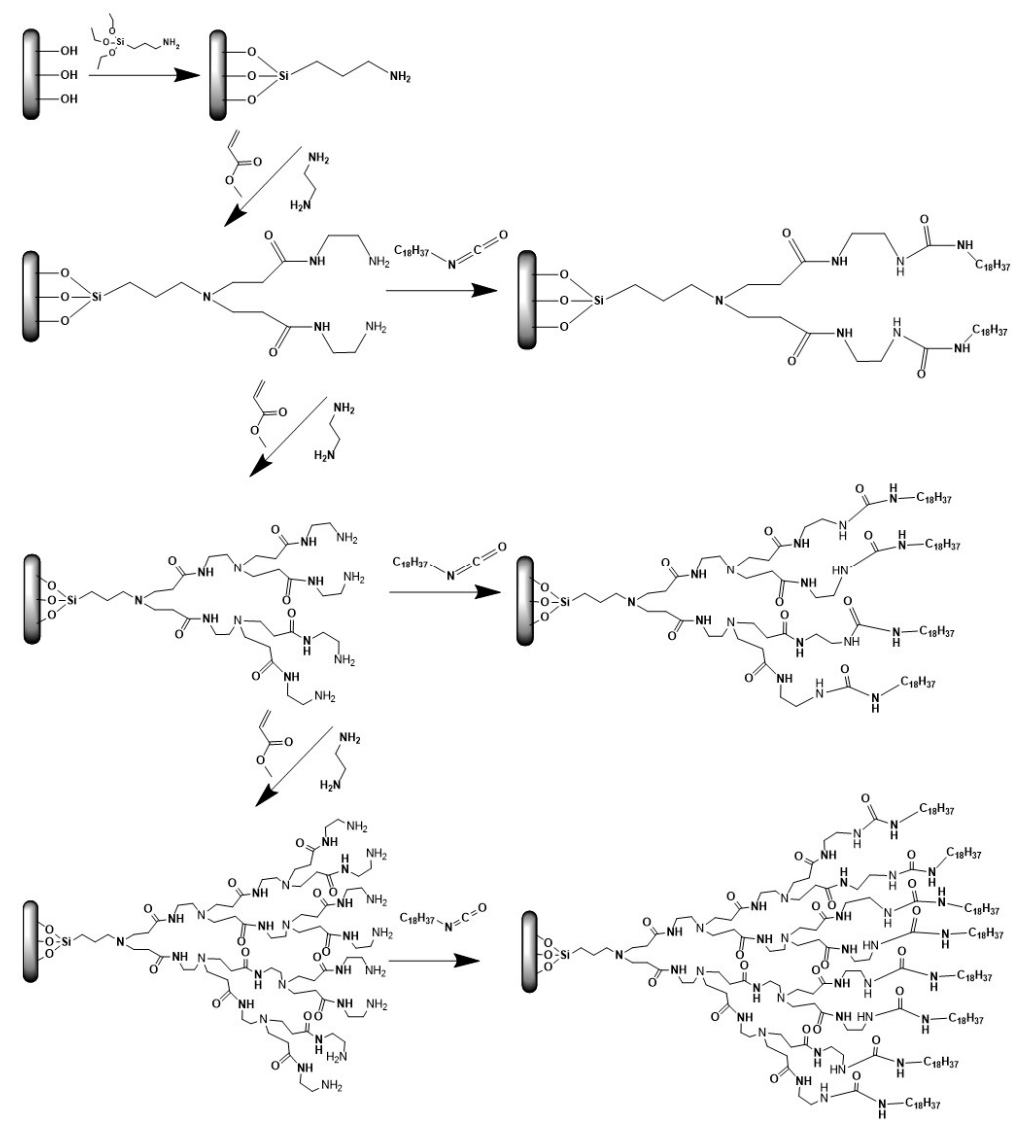

Figure 14. Formation of PAMAM dendrons on silica surface and generation of amphiphilic dendron surface-modified silica after functionalization of amino-end groups with octadecylisocyanate (Reproduced with permission from [97]; Copyright American Chemical Society, 2008). 
In another context, usually the third or the fourth generation of the dendron is required prior to the inclusion of the metal-catalyst in order to amplify its catalytic activity as is the case for recyclable gold nanoparticles that promote oxidation of alcohols [113]. In most instances, an additional stage is required: introduction of complexation sites. Specifically, PAMAM segments are phosphonated in order to establish attractive coordination sites for typical metal catalysts such as rhodium and palladium. Peripherally restructured derivatives can then readily complex with chloro(dicarbonyl)rhodium(I) or dichlorobis(benzonitrile)palladium(II). Resulting composites are applied in catalytic hydroformylation of olefins [114-116], carbonylation [117-119], hydroesterification [120] and Heck reaction of aryl bromides with butyl acrylate and styrene [121]. Another modification of the PAMAM periphery by salicylaldehyde affords a Schiff base. The reaction of the latter with $\mathrm{Mn}(\mathrm{OAc})_{2}$ - $4 \mathrm{H}_{2} \mathrm{O}$ yields an $\mathrm{Mn}$ (II) complex, immobilizes $\mathrm{Mn}$ (II) onto PAMAM-SiO $\mathrm{P}_{2}$ hybrids and leads to olefin epoxidation catalysts with increased activity (Figure 15a) [122]. Absorption and crosslinking of external amino groups with cellulase stabilizes and enhances enzymolysis efficiency [123], whereas propagation of up to third generation PAMAM dendrons from silica-coated gold nanorods produces trifunctional composites for anticancer photothermal-chemo-gene therapy and co-delivery of anticancer drugs (doxorubicin) and B-cell lymphoma 2-(Bcl-2)-targeted siRNA [124].

Aziridine polymerization is the prevailing method in order to evolve hyperbranched poly(ethyleneimine) dendrons. Pre-attachment of a reactive intermedia on the ceramic is not required $[125,126]$. Of particular interest is an unconventional, environmentally friendly technique implementing the dual functionality of compressed $\mathrm{CO}_{2}$ as reaction medium and catalyst (Figure 15b) [127].

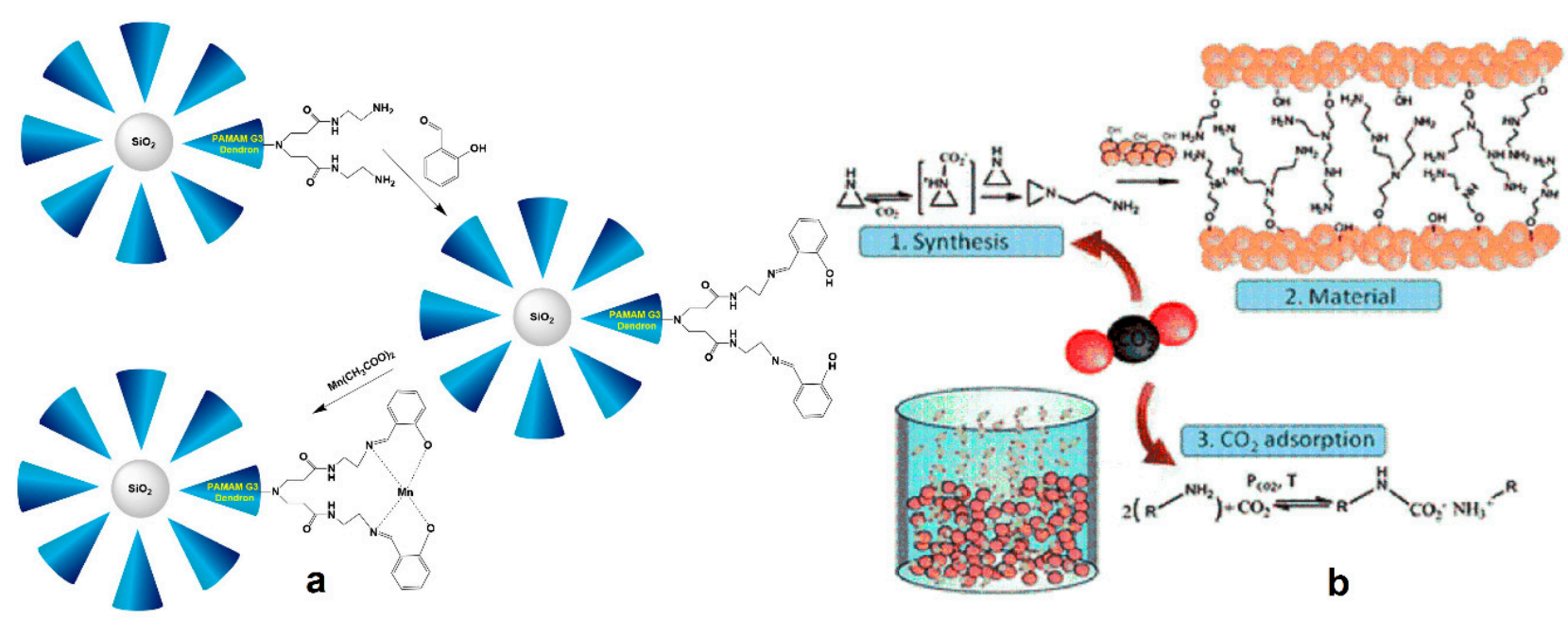

Figure 15. (a) Procedure for assembling Silica-PAMAM Dendron-Manganese Composite Catalysts. (b) Schematic representation of PEI dendron growth onto silica using $\mathrm{CO}_{2}$, and the mechanism of posterior $\mathrm{CO}_{2}$ adsorption (intended application) (Reproduced with permission from [127]; Copyright Royal Society of Chemistry, 2013).

Another compelling example of this method involves the synthetic pathway of various generations, melamine-based dendrimers directly sprouted on the surface of mesoporous silica. Initiation of this synthesis is performed by a functionalization reaction of the silica support with APES and is followed by succeeding reactions with triazinetrichloride and 4aminomethylpiperidin (Figure 16). Silica derivatives containing the primary amino groups are alternatively incubated with the solutions of the growth-promoting reagents at $4{ }^{\circ} \mathrm{C}$ for $24 \mathrm{~h}$ [128]. Replacement of 4-aminomethylpiperidin by tris(2-aminoethyl) amine (TREN) evolves dendrons suitable for $\mathrm{CO}_{2}$ absorption [129]. In a related study, combined $\gamma$-alumina membranes comprised of a mesoporous $\gamma$-alumina layer, grown into a macroporous alumina solid support, undergo a specialized activation process. Direct evolution of the dendrons off the alumina surface is once more triggered by the attachment of APES on 
the support, and is differentiated by the consecutive treatment by diisopropylethylamine and piperazine instead of 4-aminomethylpiperidin. The obtained modified membrane was further functionalized with dodecylamine in order to augment its potential in polaritybased separation applications [130].
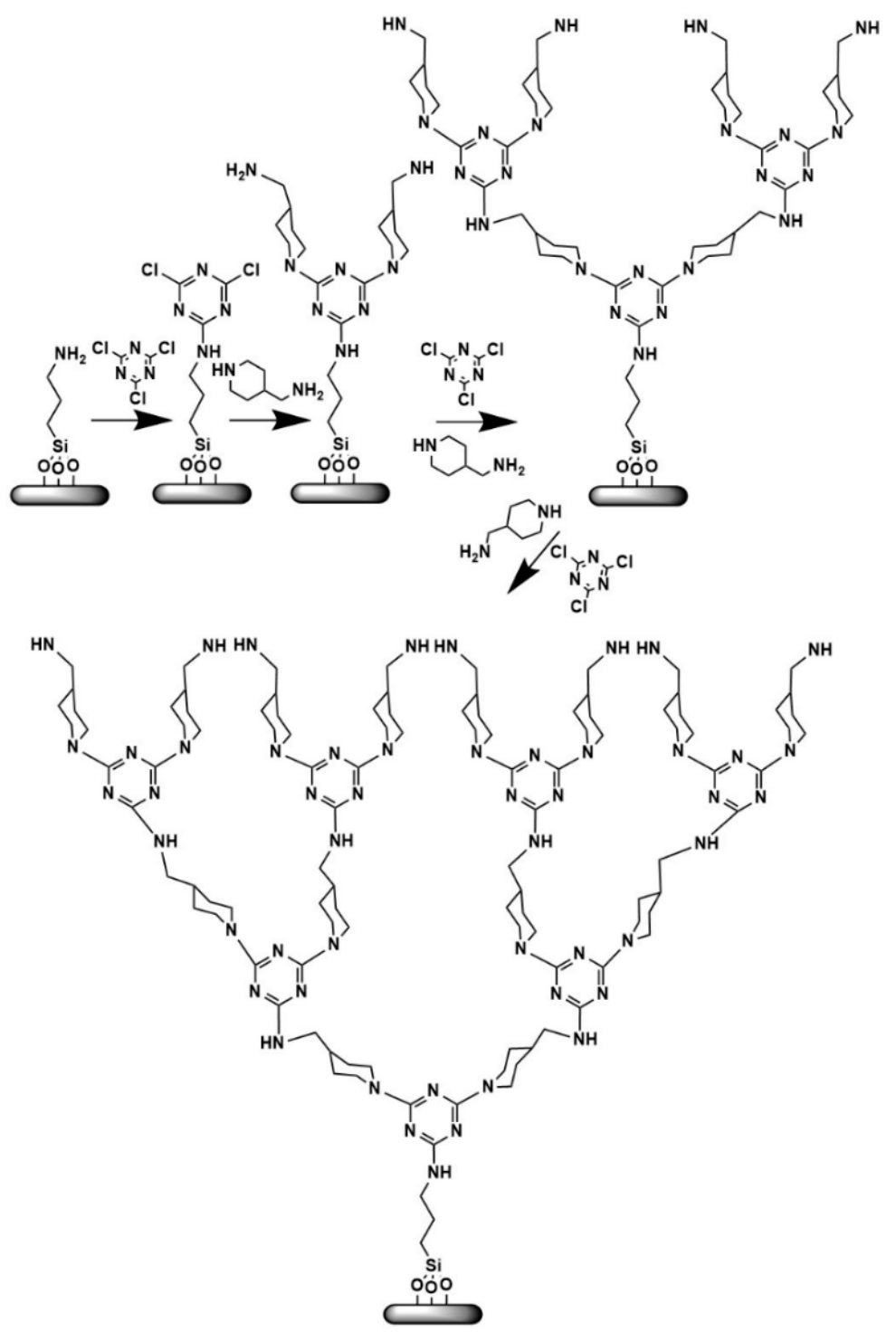

Figure 16. Evolution stages of melamine-based dendrons (Reproduced with permission from [128]; Copyright WILEY-VCH Verlag GmbH \& Co., 2004).

There is no reason for the restriction of the dendritic evolution to conventional forms only. Dendrigrafts are a distinctive and rather exotic class, and the building blocks of the internal branches are replaced by polymeric side chains may equally emanate from a suitable focal point. Tsubokawa et al. produced such a type of coating, starting by aminopropyl triethoxy silane root and "postgraft polymerization" of vinyl groups [131,132] Although entirely symmetrical branching cannot be attained through solid-phase strategies, still, it furnishes a convenient and inexpensive alternative in order to immobilize dendritic functionalities through a single sol-gel reaction onto diverse ceramic frameworks such as silica, alumina, titania, ceria, lanthania, hafnia and zirconia. 


\subsection{Sol-Gel Cross-Linking of Silyl Dendritic Polymers}

Silicon-containing dendritic polymers are a promising subcategory, distinguished for the mixed properties mostly originated from the radially multilayered copolymeric morphology and the distinctive characteristics that each constituent layer impose (Figure 17) [133]. Poly(amidoamine-organosilicon) (PAMAMOS) dendrimers present a hydrophilic poly (amidoamine) (PAMAM) molecular core and a hydrophobic organosilicon surface. They provide different structures as building blocks or active sites for various synthetic pathways depending on the chemical reactivity of their corresponding end-groups. Among them, alkoxysilyl-functionalized groups are susceptible to crosslinking chemistry, giving rise to PAMAMOS highly defined three-dimensional networks (Figure 18) [133,134]. PAMAMOS "honeycomb like" compositions are prepared through conventional cross-linking methods, which enable the formation of organosilicon structures with nanoscale dimensions, tunable sizes and shapes and high applicability in the areas of films, sheets and coatings. These sol-gel reactions follow the same two-step synthetic pattern as previously described for the dendritic moieties on the surface of ceramics: hydrolysis of alkoxysilyl (Si-O-R) end-groups to the corresponding silanols $(\mathrm{Si}-\mathrm{OH})$ and condensation of resulting silanol intermediates into final siloxane ( $\mathrm{Si}-\mathrm{O}-\mathrm{Si}$ ) bridges. The rate of the crosslinking reaction is greatly determined by several external factors and reagents, such as additional catalysts and reaction conditions [133]. For example, the optional presence of a catalyst, such as bis(2ethylhexanoate)tin and variations to curing periods and temperatures of the solvent-free PAMAMOS blocks, lead to a multiplicity of organic-inorganic nanohybrids with completely different properties depending each time on the chosen conditions. Multifunctional crosslinking agents such as tetramethoxysilane or tetraethoxysilane may be employed to increase crosslink density of the dendrimers and silica content. Moreover, controlled thermal degradation of PAMAM molecules allows the formation of porous nanocomposites, where the final pore size is dictated by the diameter of the selected PAMAM core [135].

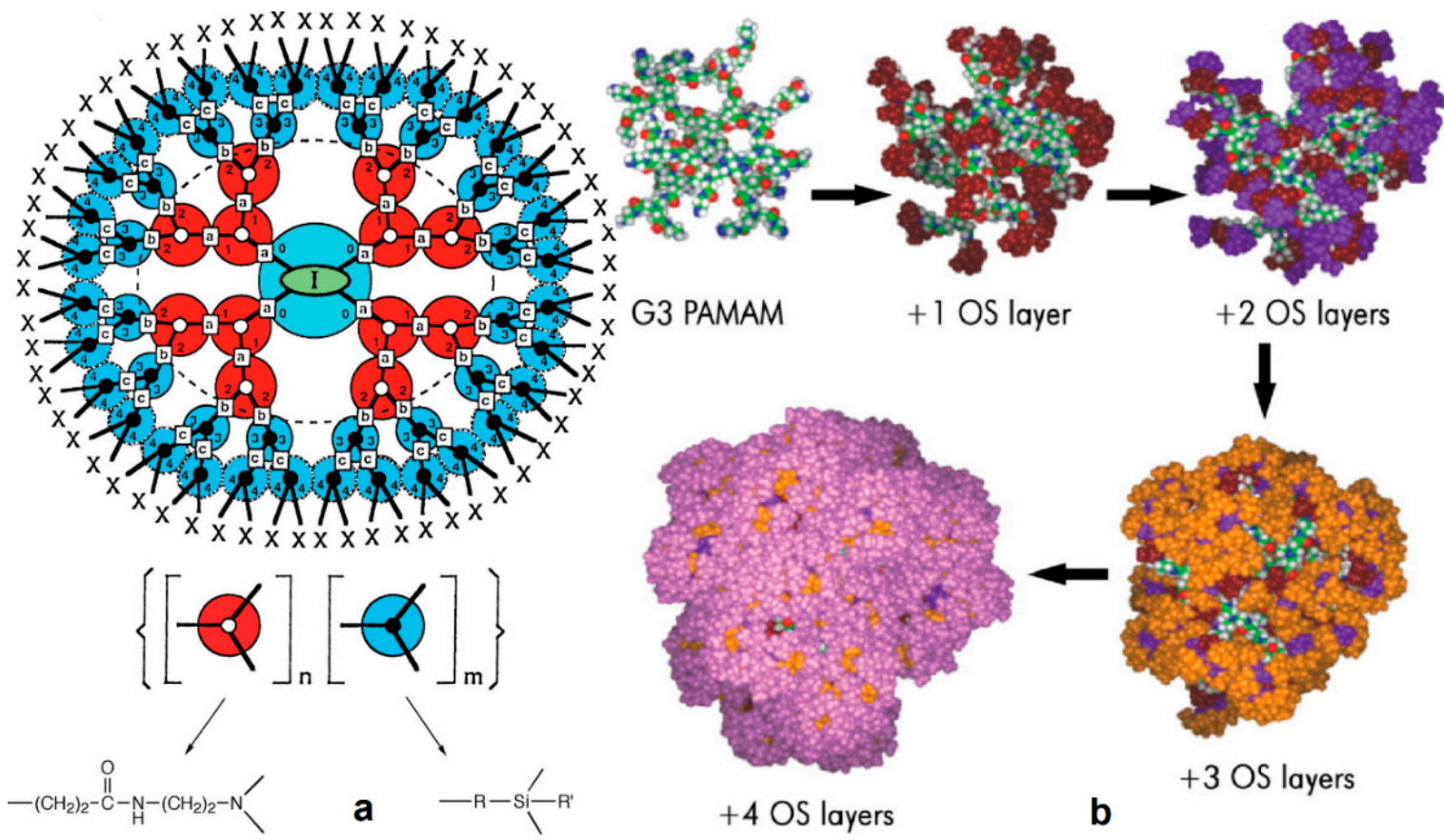

Figure 17. (a) Generalized representation of PAMAMOS dendrimer structure I: core; X: end-groups; 1, 2, 3, 4, denote generations; letters: a, PAMAM-PAMAM bonds b, PAMAMOS bonds c, OS-OS bonds. (b) Molecular models of Generation 3 PAMAM interior (green-red-white-blue) with increasing number of organosilicon exterior layers. First layer brown; 2nd layer purple; 3rd layer yellow; 4th layer magenta (Reproduced with permission from [133]; Copyright WILEY-VCH Verlag GmbH \& Co., 2006). 


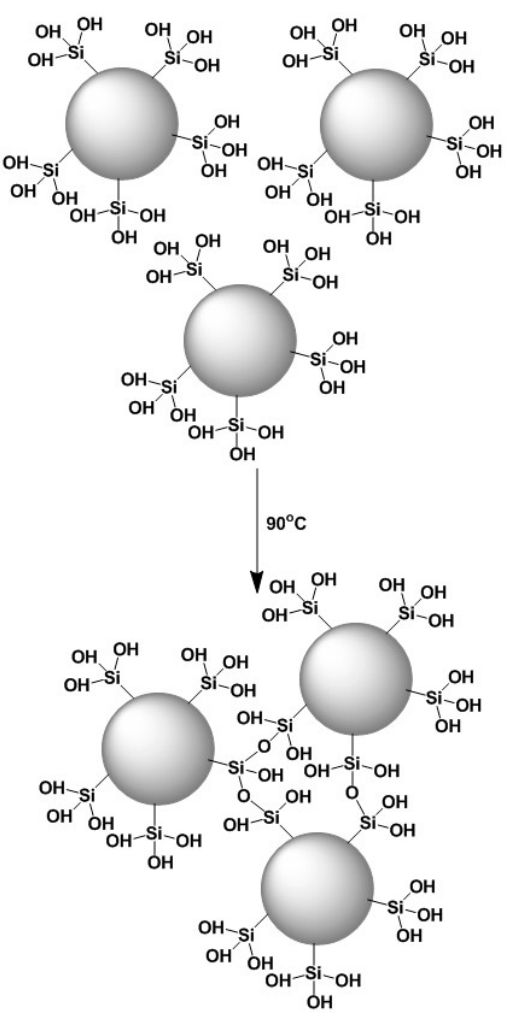

Figure 18. Formation of honeycomb-like PAMAMOS networks from silyl dendrimer precursors (Reproduced with permission from [133,134]; Copyright WILEY-VCH Verlag GmbH \& Co., 2006; American Chemical Society, 2002).

Hybrid, silica-containing hyperbranched polymers can be also be produced by the aid of PEIs (MW 5000 or 25,000) and 3-(triethoxysilyl)-propylisocyanate as the silica precursor in a $\mathrm{N}, \mathrm{N}$-Dimethylformamide (DMF) or chloroform solution. The crosslinking density remarkably relies on ethoxysilylated polymer end groups reactivity; hydrolysis and concomitant polycondensation rates, that ultimately drive the architecture of the silica-PEI network. Hybrid products can be exploited, either as they are or impregnated/covalently bound to another appropriate ceramic substrate. They also offer the option of pyrolytic dendritic template removal, affording nanoporous silica powders with advanced textural characteristics. Nanomaterials produced by sol/gel processes display similar morphology characteristics, such as surface areas varying between 300 and $500 \mathrm{~m}^{2} \cdot \mathrm{g}^{-1}$ and a pore diameters of around $2 \mathrm{~nm}$ [136]. Cohydrolysis and polycondensation is not limited to dendritic polymers containing solely silicon heteroatoms. Phosphorus dendrons of first, second, and third generation bearing ethoxy silane groups at their apex cross-link with tetraethoxy silane (TEOS) leads to silica xerogels with adjustable textures too [137]. Very recently it has been discovered that even "traditional" (i.e., not containing silicon) hyperbranched PEIs form nanocomplexes via hydrogen bonding with orthosilicic acid produced by the acid hydrolysis of TEOS. These nanostructures grow faster at neutral $\mathrm{pH}(7.5)$ and substantially slower at a lower $\mathrm{pH}(\mathrm{pH} 5)$ and transform to hydrogels. When dried they became organoceramic xerogels. Active ingredients may be incorporated into the dendritic cavities at any step of the process. In the framework of a multinational European Project (Novel Marine Biomolecules Against Biofilm Application to Medical Devices: NoMorFilm) this procedure was tested on titanium microporous coating of a stainless-steel model orthopaedical implants with excellent results [138].

\subsection{Biomimetic Reactions}

Evolution has equipped living organisms with advanced self-constructing capabilities in order to secure better survival possibilities. Self-assemblage biogenic mechanisms are 
introduced for the development of complex organizations. The process where biological molecules activate and control independently a cellular pathway leading to the construction of metal nanoparticles is called biomineralization [139]. Biosilicification, the analogous procedure for biogenic formation for silica-based materials, occurs naturally in many microorganisms too, either terrestrial (higher plants) or aquatic ones (diatoms, sponges). It proceeds rapidly, under mild aqueous conditions, such as ambient temperature, pressure and neutral $\mathrm{pH}$ [140]. Biogenic silica occurs in a great diversity of nanopatterned frameworks, with varying sizes, shapes and organizations that are species-specific and malleable in nature, all deriving from the single reaction of silicic acid condensation [141]. This "manipulating siloxane bridge formation" advantage is attributed to the mediation of several biopolymers $[142,143]$. Specifically, it is established that post-translationally modified polycationic peptides, such as silaffins and R5 peptides, both isolated, from diatom cell walls, precipitate silica nanospheres almost instantly and in a peptide concentration-dependent fashion. There are numerous subsequent studies that successfully used conventional synthetic substitutes of biomolecules to imitate the evolution of biocomposites. For instance, a variety of homopeptides such as poly(arginine) and poly(lysine) [144] and a combination of triethanolamine and cetyltrimethylammonium chloride [145] can serve as biomimetic templates, forming silica nanoparticles with controlled specifications.

Amine-terminated dendrimers of various generations constitute exceptional templates that stand out for their similarity to proteins and tunable design that is primarily dictated by the high concentration of well-localized nitrogen functionalities, which resemble the units found in their biological counterparts and are responsible for silica nanospheres production [142]. For instance, poly(amidoamine) PAMAM and poly(propylene imine) PPI represent popular matrices for the formulation of nanopatterned silica (Figure 19) and alumina (Figure 20) [146]. The silica ratio of the final aggregated nanoproduct depends highly on the number of amino groups of the selected dendrimer. Knecht et al. described biomimetic sol-gel reactions as a powerful method to produce PAMAM/PPI-Si nanospheres. The sol-gel reaction proceeds at room temperature through the addition of metastable silicic acid into the dendrimer solution. Use of a phosphate buffer is required to obtain a $\mathrm{pH}$ of 7.5. Organic (dendritic) scaffolds are encapsulated into the gradually forming silica nanospheres and then the hybrids precipitate from a water solution in a way similar to that described before for the case of bioactive peptides. The outcome of the reaction and the production of nanospheres with distinct and specific dimensions hangs on the appropriate selection of dendritic reagents, with proper amine concentration suitable conditions and the presence of inorganic salts [143]. Given the fact that hydroxylterminated PAMAM analogues do not cause silica precipitation, it is ascribed exclusively to the presence of amino groups.
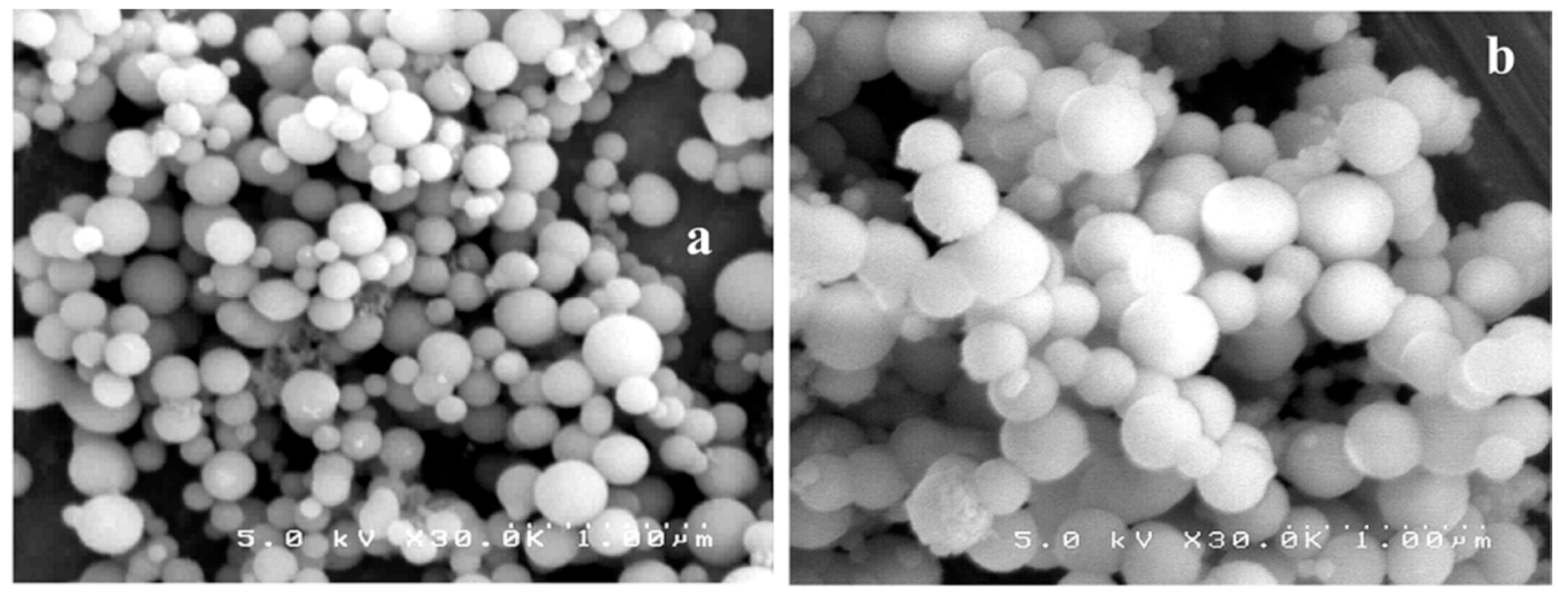

Figure 19. SEM micrographs of silica nanospheres, biomimetically templated by Amine-Terminated Dendrimers (a) G4 PPI and (b) G4 PAMAM (Reproduced with permission from [142]; Copyright American Chemical Society, 2004). 


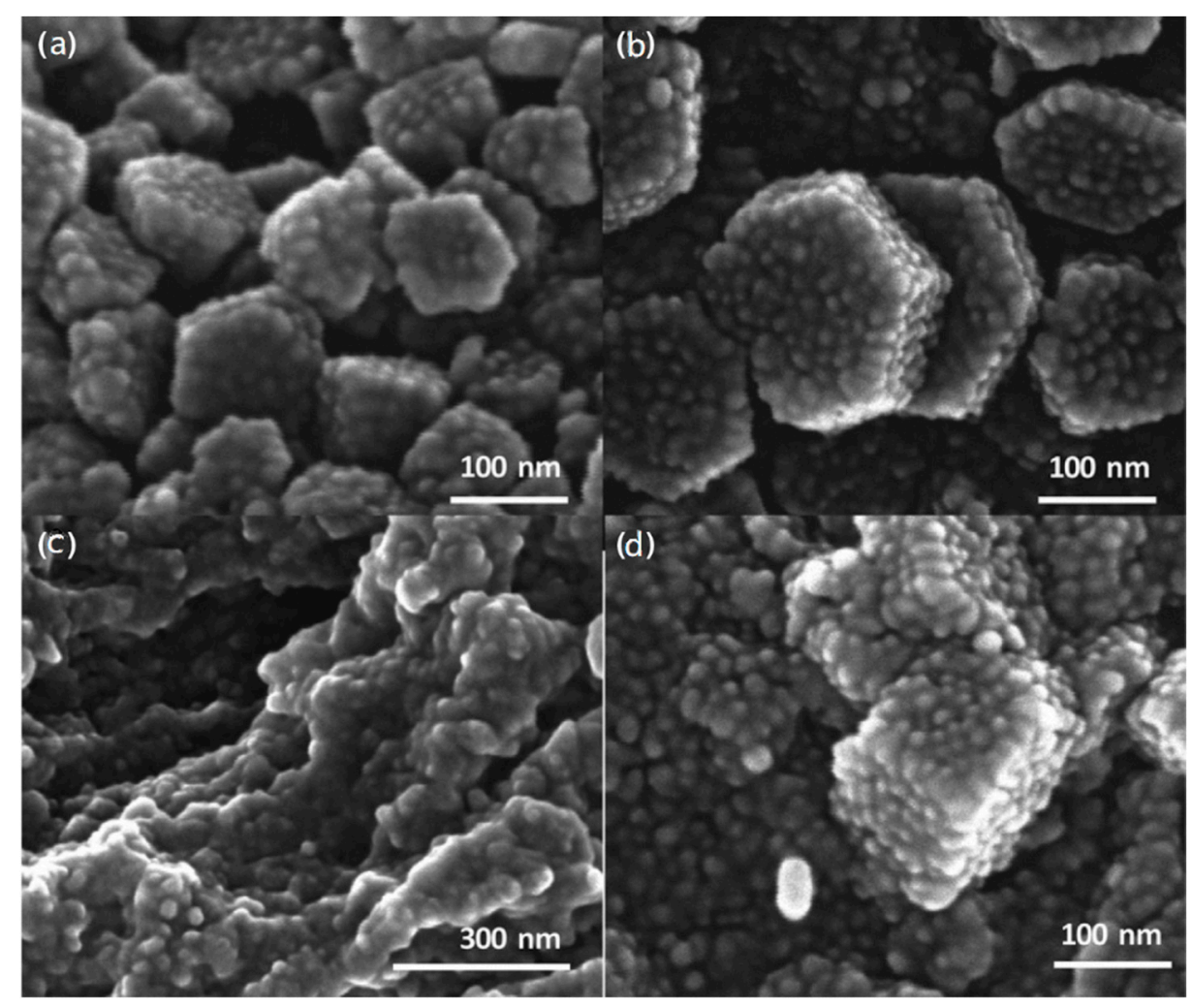

Figure 20. SEM micrographs of alumina nanospheres templated by hyperbranched PEI for different quantities of nano-dispersed boehmite ((a) 0.02, (b) 0.04, (c) 0.06, and (d) $0.08 \mathrm{~g} / \mathrm{mL}$ ) (Reproduced with permission from [146]; Copyright The American Ceramic Society, 2018).

Poly(amidoamine), PAMAM (G5.5) anionic starburst dendrimers functionalized with surface carboxylate groups have also been used as templates for the synthesis of hybrid nanocrystalline $\mathrm{ZrO}_{2}, \mathrm{CeO}_{2}$ and $\mathrm{Y}_{2} \mathrm{O}_{3}$ [147]. These ceramic powders were obtained through hydrolysis of the methylester-terminated dendrimers in the presence of stoichiometric $\mathrm{NaOH}$ volumes. The selection of the highest possible dendrimer generation is essential for the inhibition of extensive crystallization and the control of the final morphology of the nanoparticles. Thermal treatment at $600{ }^{\circ} \mathrm{C}$ for at least $2 \mathrm{~h}$ was a necessary step for the shaping of the amorphous nanoproduct into highly ordered spherical nanocrystalline powders. As long as the encapsulated dendritic polymers and their optional active guests in their internal cavities retain their properties, the resulting nanomaterials may be applied in various processes, including environmental remediation and catalysis. Nanospheres obtained through non-symmetrical analogues serve as inexpensive alternatives for both organic and inorganic pollutant sorption and water decontamination. Hyperbranched Poly(ethylene-imines) were proven ideal matrices as they caused silica nanosphere precipitation even in the absence of phosphate buffer, albeit to a noticeably lesser degree. The resulting hybrids removed toxic heavy metal ions $\left(\mathrm{Pb}^{2+}, \mathrm{Cd}^{2+}, \mathrm{Hg}^{2+}, \mathrm{Cr}_{2} \mathrm{O}_{7}{ }^{2-}\right)$ and polycyclic aromatic hydrocarbons (pyrene, phenanthrene) from water [148]. For the attainment of catalytic activity, templated metal nanoparticle nucleation occurs by reduction of trapped ions prior to inorganic shell organization. Composites containing $\mathrm{Au}$ and $\mathrm{Ag}$ successfully catalyzed 4-nitrophenol reduction oxidation of methylene blue and selective oxidative transformation of benzyl alcohol to benzaldehyde [149].

An evolution of the above procedure proposes the fusion of two different biomimetic processes, biosilicification and biomineralization in one pot synthesis procedure. Both syntheses are regulated by the same hyperbranched polymer in the role of protein substitute [150]. In this way, silica-PEI-silver nanoparticle composites have been assembled, retaining antibacterial activity, catalytic properties and protracted release profile of the respective metal-dendritic polymer complexes. The synthesis of these highly compartmen- 
talized ceramic-organic metal nanocomposites is attained via two successive steps that use the same functional scaffold: PEI Mr = 25,000 (Figure 21). At first, silver ions absorbed into the PEI pockets undergo reduction to metallic silver (core), then silica precipitation occurs from the silicification in the periphery of the dendritic polymer (shell). The bactericide activity of these hybrid nanoparticles is of particular interest. E. coli, P. aeruginosa and S. aureus assays established that Si-PEI-Ag nanoparticles efficiently prevented their proliferation, consistent with the concept of conservation of the complexes features despite their enclosure into silica capsules.

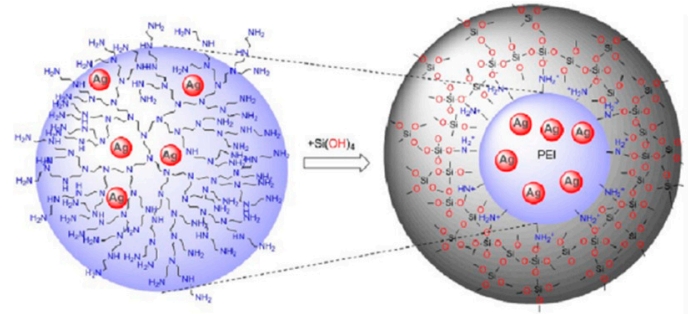

a
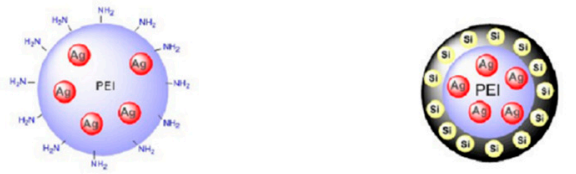

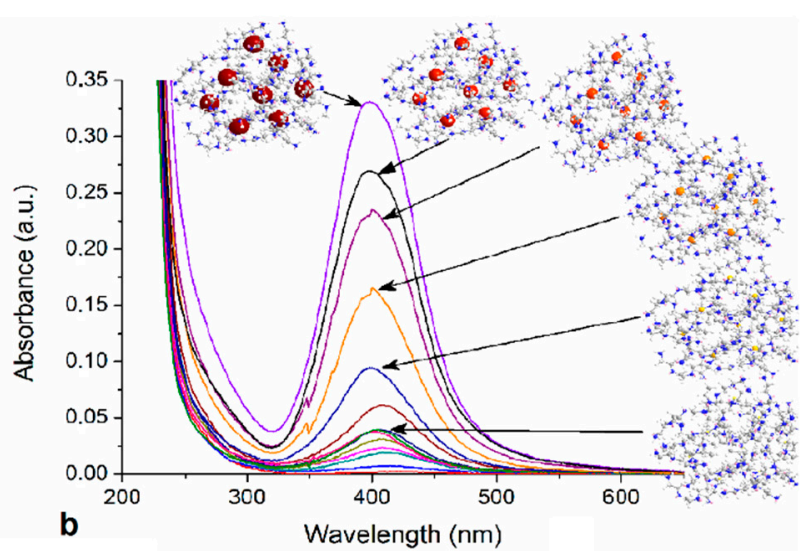

Figure 21. (a) Schematic representation of hybrid silica-PEI-Ag nanoparticles; (b) UV-Vis spectra of silica-PEI-Ag nanoparticle suspension in different time periods (Reproduced with permission from [150]; Copyright Elsevier, 2018).

Bearing in mind the large impact of electrostatic forces between dendrimers and silica precursors, a similar influence in the size and shape of the biomimetically produced silica particles is rationally expected. Ionic strength plays a pivotal role. In the case of PAMAM, for example, for all generations (G1-G6), it has been established that silica corpuscles get bigger with augmenting phosphate concentrations (Figure 22a) [143]. On top of that, at $\mathrm{pH} 7.5$, when the phosphate buffer was replaced with individual alkali metal-chlorine solutions, SEM analysis unveiled a similar linear increase in particle diameter with increasing concentrations up to $100 \mathrm{mM}$ (Figure 22b). Smaller cations up to $\mathrm{K}^{+}$generated typically larger composites, most probably due to preferential interaction with a single silanol group. In contrast, larger cations tend to affect multiple silanols, provoking imperfect surface coverage and limited charge neutralization. These results highlight further the role of neutralizing agents on the growth of silica nanospheres, i.e., securing as minimal as possible electrostatic repulsions and as much as possible free space for unhindered agglomeration.

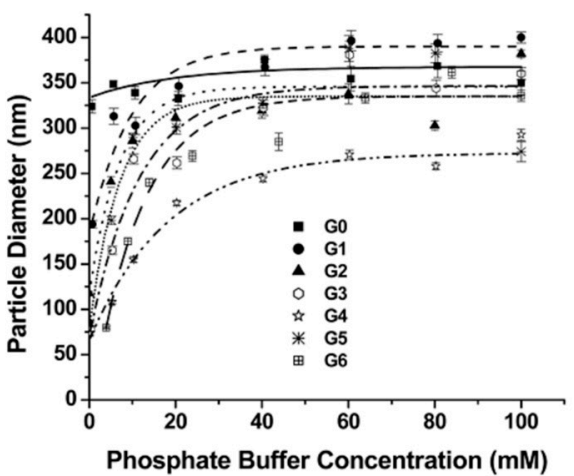

a

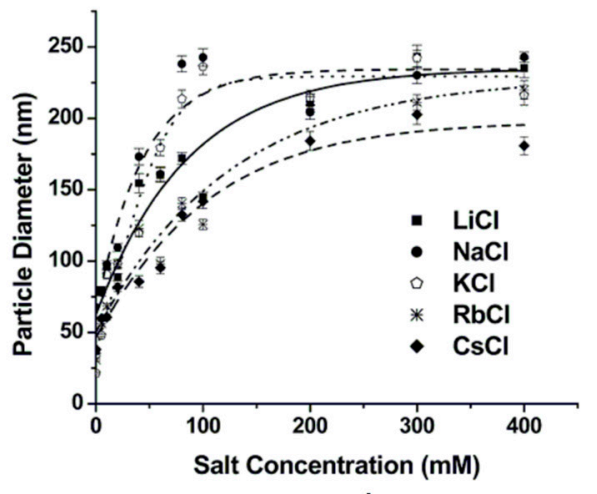

b

Figure 22. (a) Particle size of nanospheres produced by different PAMAM generations as a function of phosphate buffer concentration (b) as a function of salt concentration for different alkali metal chlorides (Reproduced with permission from [143]; Copyright American Chemical Society, 2005). 
Dendritic scaffolds are likely to deliver many roles in the fulfillment of the silica condensation reaction. Generally, polypeptides, polyamines and polyamidoamines are partially protonated $\left(\mathrm{NH}_{3}{ }^{+}\right.$groups) at neutral $\mathrm{pH}$, suggesting that an equilibrium is achieved between the opposing charges of the template and the surface of developing silica [151-153]. This neutralization results in the creation of an extensive network, with $\mathrm{NH}_{3}{ }^{+}, \mathrm{Si}_{-}-\mathrm{O}^{-}$ interacting groups and solubilizing water molecules. These interactions also drive the incorporation procedure of the matrices within the silica nanospheres. Overall, silica PEI-nanospheres display a negative potential at low $\mathrm{pH}$ that reaches the value of nearly $-80 \mathrm{mV}$ at $\mathrm{pH} 11$, as indicated by zeta-potential measurements. In addition, the isoelectric point (IEP) after pyrolysis is nearly 2, similar to the IEPs typically encountered in the case of amorphous silica. The presence of the dendritic core in the nanospheres shifts the IEP towards higher $\mathrm{pH}$ values. Indeed, the hybrid organic-inorganic nanospheres show an IEP of roughly 8, persistent with the presence of positively charged amino groups. These hybrid nanocomposites present a positive surface potential of nearly $+50 \mathrm{mV}$ at $\mathrm{pH} 2$, that decreases to about $-70 \mathrm{mV}$ at $\mathrm{pH} 11$.

Besides creating novel ceramic nanostructures, dendritic polymers can serve as crystal modifiers for the biomimetically controlled production of nanoscale biomaterials. The development of these nanoproducts has attracted increasing interest recently, especially in the field of drug delivery systems and biomolecule expression. Aquasomes, for instance, are nanocrystalline ceramics with flexible surfaces that can be appropriately modified with carbohydrates in order to interact with specialized proteins and pharmaceuticals and to transfer them to tissue-specific areas [154,155]. An interesting relevant study attempts to fabricate spherical hydroxyapatite nanocores (Figure 23) by employing carboxylic acidterminated PAMAM of 3.5 and 4.5 generations as starting materials for the production of hemoglobin-carrying aquasomes [156]. Noteworthily, hydrothermal treatment with generation 5.5 PAMAM drives the production of highly crystalline hydroxyapatite nanorods [157]. In general, dendritic PAMAMs, due to amido groups in their external surface, induce hydroxyapatite nanoparticles with an adjustable size and shape according to their generation through a hydrothermal crystallization. Increasing PAMAM generation number from G1.0 to G4.0 causes a decrease in the particle size from 82 to $38 \mathrm{~nm}$ respectively. In parallel, a transition occurs in the resulting shape from rod-like to ellipsoid-like [158]. Analogous effect is observed with increased concentrations of PAMAM G4.0. On the other hand, their polyhydroxy-substituted analogs in most cases formulate elliptical particles with an average grain size of about $20 \mathrm{~nm}$ and rarely short nano-rods with an average length of about $30 \mathrm{~nm}$ and an average width of about $25 \mathrm{~nm}$ [159].

Cationic fourth generation diaminobutane poly(propylene imine) dendrimers (DAB) strongly favor the formation of hydroxyapatite over all the other possible calcium phosphate crystalline phases [160]. The crystallization process may be regulated by introducing different thermal conditions and dendrimer:calcium ratios (Figure 24). The resulting nanoparticles display a characteristic elongated hexagonal rod-like configuration, with dimensions that are largely dictated by the particular reaction conditions. For example, increasing the temperature of hydrothermal processing from 80 to $130{ }^{\circ} \mathrm{C}$ leads to a noticeable lengthening, while maintaining room temperature conditions induces a fine nanostructure with distinctive mean length and width values (i.e., 11 and $5 \mathrm{~nm}$ ). The presence of DAB dendrimers plays a vital role in the homogeneity of the developing hydroxyapatite nanocrystals, as well as in energy conservation and cost reduction of the process. Conventional hydroxyapatite crystal generation in the absence of dendritic mediators requires high temperatures (i.e., $130^{\circ} \mathrm{C}$ ) and exhibits a highly inhomogeneous morphology with broad particle size distribution. 

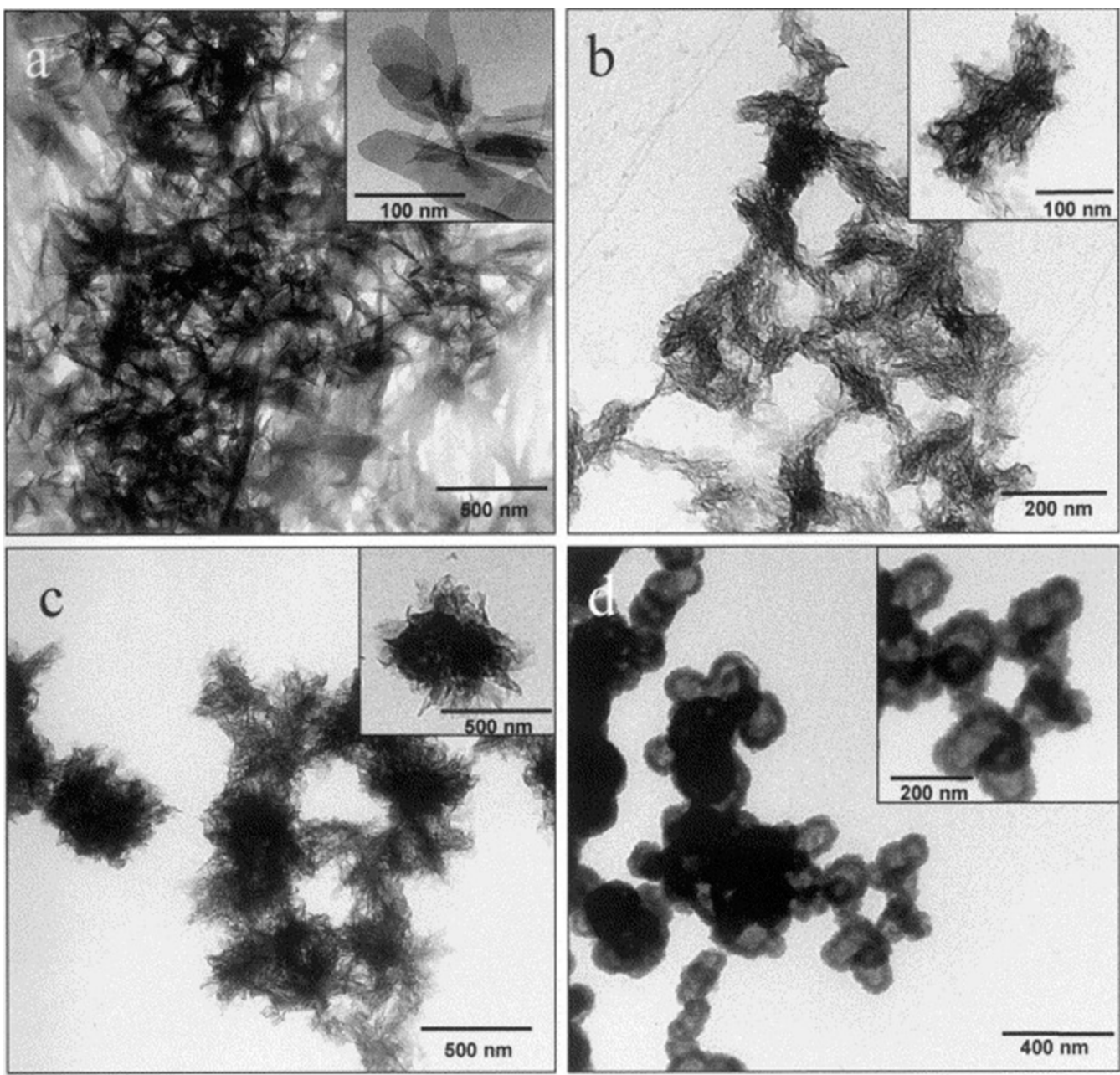

Figure 23. TEM image of hydroxyapatite prepared by self-precipitation from SBF. (a) Direct precipitation from SBF at $\mathrm{pH} 9.0$ in absence of dendrimer. (b) Self-precipitation in the presence of 4.5 generation PAMAM dendrimer from SBF at $\mathrm{pH}$ 7.4. (c) Self-precipitation in the presence of 3.5 generation PAMAM dendrimer from SBF at $\mathrm{pH}$ 8.5. (d) Self-precipitation in the presence of 3.5 generation PAMAM dendrimer from $\mathrm{SBF}$ at $\mathrm{pH}$ 8.0. Insets in all figures show typical hydroxyapatite particle shape and morphology under magnification (Reproduced with permission from [146]; Copyright The American Ceramic Society, 2018).

Hyperbranched PEI bearing long alkyl chains, when mixed with single-chain surfactants such as octadecylamine, haxedecyl trimethylammonium bromide and sodium dodecyl sulfate afford a well-defined dendrimer/HAP biocomposite that mimics principal structural and mechanical properties of bones, such as plastic deformation and high stiffness and strength. The selected surfactant clearly affects not only the size and shape of the resulting hydroxyapatite composite, but also its mechanical idiosyncrasy, with octadecylamine and haxedecyl trimethylammonium bromide yielding composites exhibiting the highest toughening [161]. 

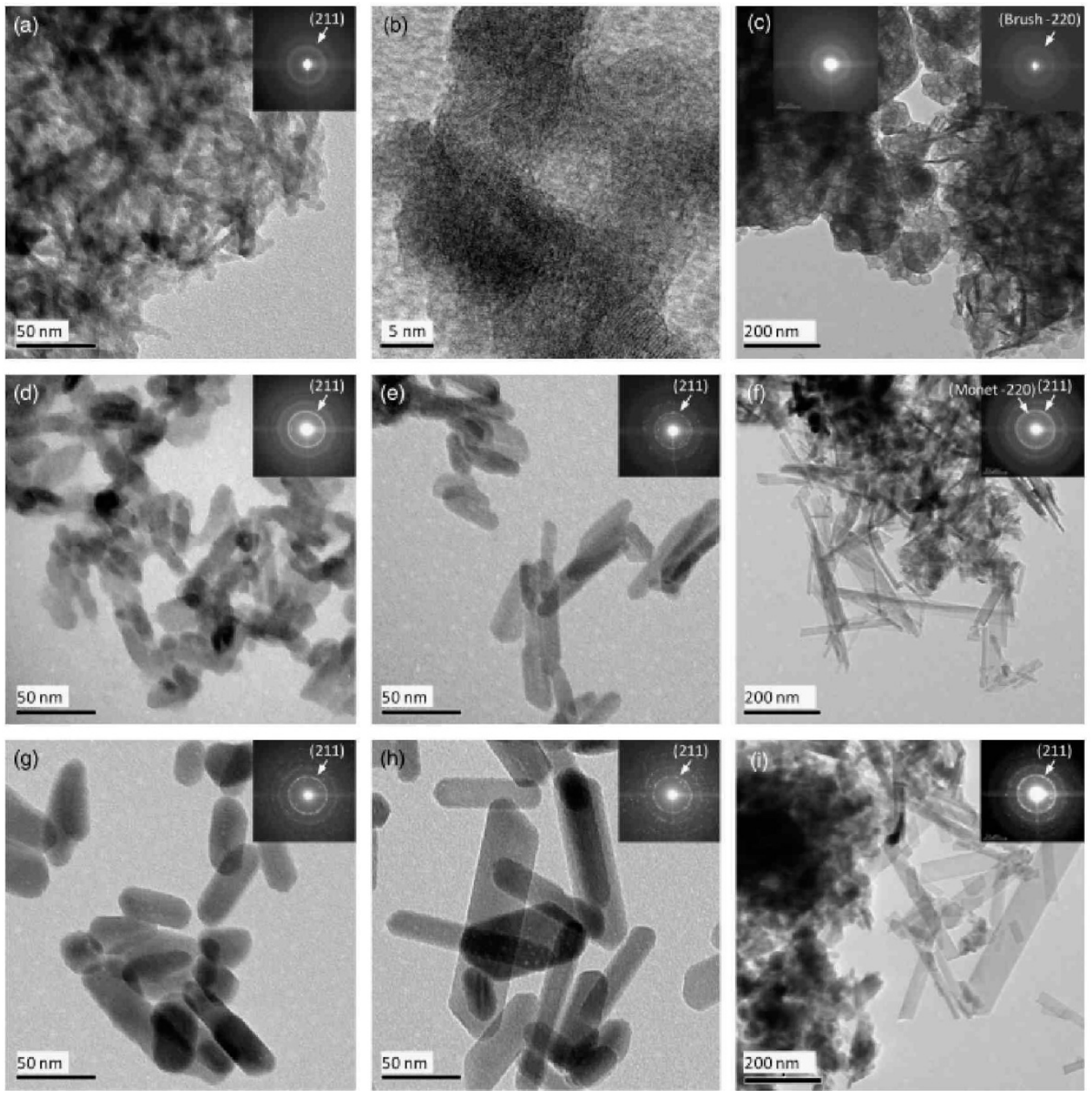

Figure 24. TEM images and respective selected area electron diffraction patterns of nanoparticles obtained under different conditions. Upper row for samples prepared at room temperature: (a) HAP dendrimer:calcium 1:1, (b) high resolution image, and (c) control (without DAB); middle row for samples hydrothermally treated at $80^{\circ} \mathrm{C}$ : (d) HAP dendrimer:calcium 2:1, (e) HAP dendrimer:calcium 1:2, and (f) control; lower row for samples hydrothermally treated at $130{ }^{\circ} \mathrm{C}:(\mathrm{g}) \mathrm{HAP}$ dendrimer:calcium 2:1, (h) HAP dendrimer:calcium 1:2, and (i) control (Reproduced with permission from [160]; Copyright The American Ceramic Society, 2011).

\section{Improvement Strategies for Performance Optimization}

As discussed above, the performance of filters in applications such as water purification is directly proportional to the impregnation percentage of the dendritic polymer. The latter is governed by the particular pore architecture of the ceramic by the $\mathrm{pH}$ and the ionic strength of the immersion solution but mainly by its concentration $[87,162,163]$. A common emerging problem during the impregnation process is the rapid pore blocking which is aggravated abruptly with viscous dendrimeric derivatives as concentration of the coating solution raises [61], due to the intrinsic spongy labyrinthine configurations of the porous structures. Another issue encountered at denser immersion solutions is the structural breaks/cracks that mark the final composite product, and can undermine the filter absorption performance. These deformations originate from the stress applied during the drying process. Smoother, flawless, ceramic surfaces with optimum absorption properties (Figure 25) can be attained through a simple multiple immersion technique to solutions of gradually increasing concentrations. This method combines both adequate 
polymer loading with controllable porosity decrease, and avoids pore blocking and all the other disadvantages of immersion in concentrated media.
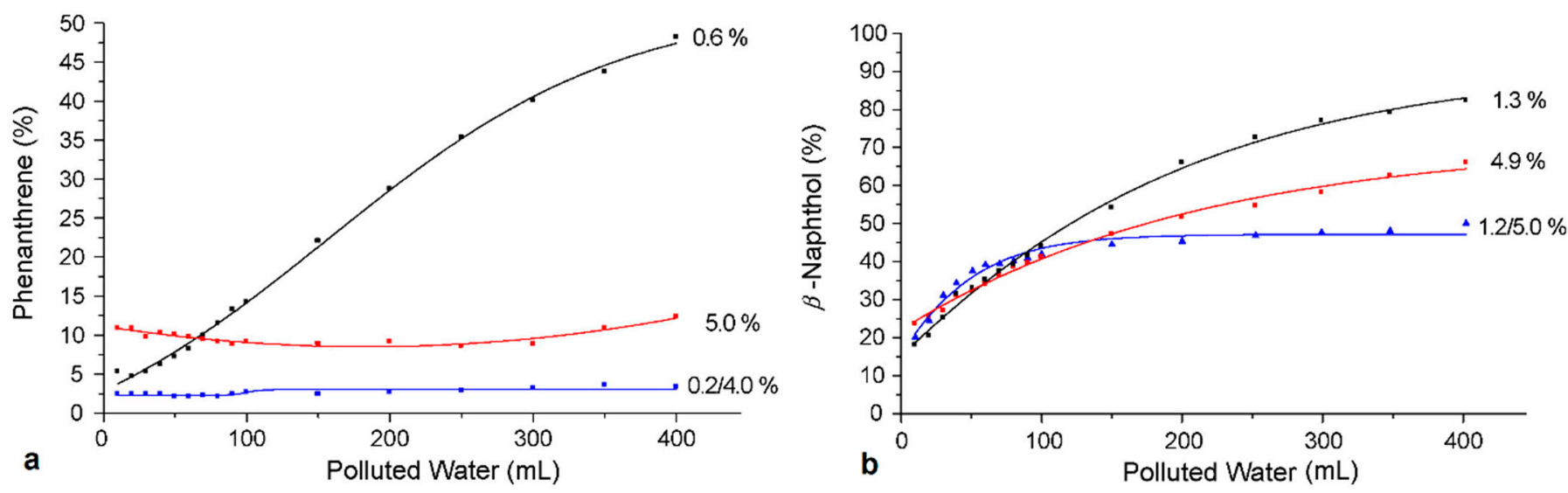

Figure 25. Percentage of phenanthrene (a) and $\beta$-naphthol (b) remaining in water in continuous filtration through filters impregnated by different percentages of octyl-substituted hyperbranched PEI employing a single or a two-step immersion stage (Reproduced with permission from [61]; Copyright Elsevier, 2008).

The involvement of dendritic polymers in the evolution of original nanoscale species with optimized characteristics is raised continuously. Their full biomimetic potential is exploited in parallel. Knecht et al. were the first to introduce $\mathrm{pH}$ regulating agents, such as phosphates or $\mathrm{HCl}$, as a means to achieve optimal ionic strength and $\mathrm{pH}$ stabilization, as well as to control the final nanosphere dimensions [142]. The idea of double biomimicry gave rise to the synthesis of more complex inorganic/organic/inorganic nanostructures that generally exhibit combinatorial, enhanced properties [150]. These hybrid materials usually carry a dendrimeric matrix stuffed by metal nanoparticles and surrounded by a ceramic shell. Each single biomimetic reaction is successively and independently carried out in order to retain the full properties of the two constituents. It is possible to micromanage the specifications of the final hybrid product, such as the size and shape of both inner metal and outer ceramic particles, the overall composition and the porosity and pore dimensions of the inorganic segment, by adjusting either the biomineralization incubation time or the ratios of the silicification precursor towards the dendritic matrix or the molecular weight of the latter. For example, higher molecular weight of the organic core causes faster formation of metal nanoparticles and optimal catalytic performance of the final product. Thus, biomimetic process optimization can offer unique hybrid solutions with both combinatorial and manageable structural characteristics, evolving nanomaterial synthesis to a whole new level.

Numerous factors can perturb the perfectly symmetrical growth process of the dendritic polymer onto the ceramic surface, affecting the overall properties of the final nanoproduct. For example, side reactions usually co-occur with the propagation pathway of PAMAM on the silica surface, inducing thus major structural diversifications such as dimer and intramolecular cyclization (Figure 26a) [96]. Specifically, a high density of trihydroxy aminopropyl silane molecules bond to the ceramic surface leads to an equally high concentration of precursor- "dendron core" amino groups, which in turn cause serious formational defects. Lower density of dendron-generating amino groups leads to a decrease in steric hindrance, as well as an increase in the in-between distance of secondary amino groups of the dendritic branches, thus preventing the formation of undesired inter-dendron and intra-dendron cross-linked structures in higher generations (Figure 26b). This effect can be successfully avoided through the co-immobilization of 3-(triethoxysilyl) propionitrile on silica, which serves the role of the "spacer", reduces the "dendron-core" amino group density and thereby improves the whole evolution procedure. 


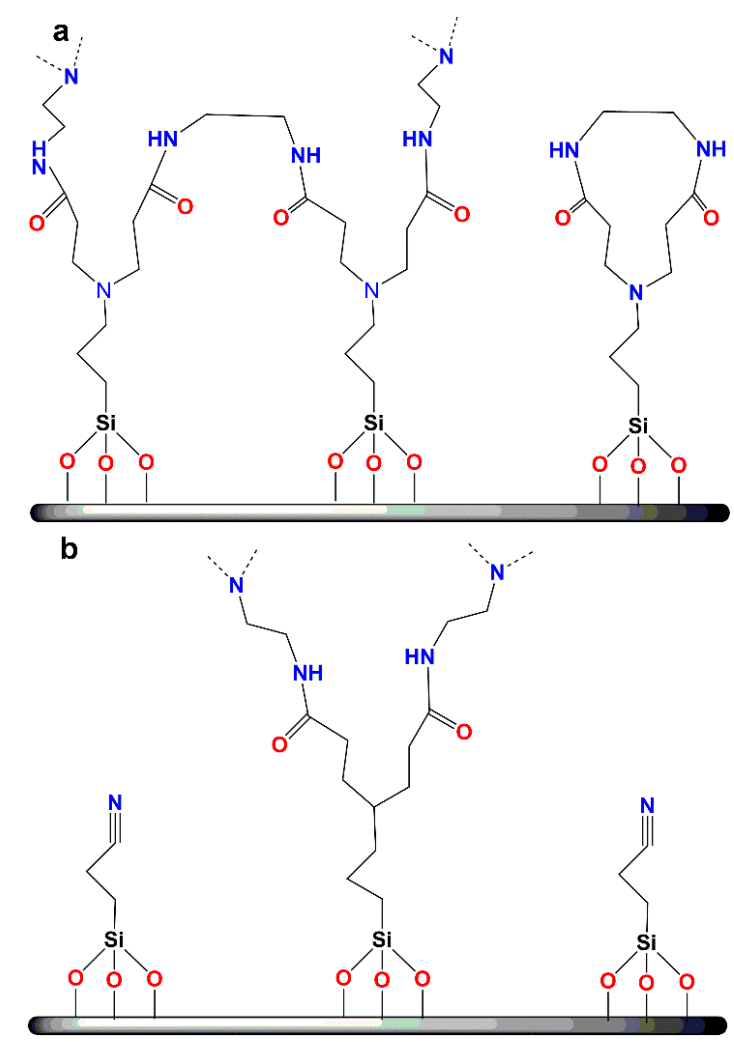

Figure 26. (a) Common structural defects occurring during the dendron propagation reaction; (b) introduction of triethoxysilyl propylonitrile as a spacer for the elimination of cross-linking structural defects (Reproduced with permission from [96]; Copyright American Chemical Society, 2004).

The non-uniform shape and irregular size of the pores are two other factors contributing to the steric/crowding effect. A prominent solution includes the exploitation of silica bearing highly ordered, hierarchical channels (e.g., hexagonally packed) that shows narrow size distribution, such as MCM-41, and SBA-15 [164,165]. These afford dendron development up to fourth or higher generations with negligible structural defects.

\section{Concluding Remarks-Perspectives}

Hybrid dendritic/ceramics materials offer a multitude of perspectives in a variety of interdisciplinary fields replacing traditional, non-functionalized materials that usually suffer from structural inhomogeneity, absorption instability and thus limited applicability $[166,167]$. The use of dendritic polymers as additives is now widely accepted. In fact, there are several studies substantiating their superiority as stabilizing agents that do not undermine the physicochemical properties of the guest molecules. Some applications covered herein are summarized in Table 1. A plethora of perspectives are envisaged. For instance, PAMAM polymers have been used as stabilizers of semiconductor quantum dots, CdS synthesized at the nanometer-scale [168]. The stabilization effect lies in the effective solvation of these highly insoluble nanoclusters, avoiding precipitation, which occurs in the absence of PAMAM. Dendritic polymers also stabilize colloidal suspensions of gold by in situ reduction of its ions encapsulated into their cavities [169]. Silver nanoparticles may be obtained too through a reduction of cations encapsulated into dendrigrafts, even without a reductant [170]. Optical and structural characteristics of these nanoparticles, such as UV-Vis absorption spectrum, eventual light emission, size and shape are determined by the chemical nature of the dendritic matrix and the host/guest concentrations ratio. Dendritic polymers are furthermore well-known for their ability to deliver an immense variety of colored metal complexes. The composites with ceramics retain this characteristic, along with luminescence properties according to the metal particle conformation. These hybrid sen- 
sors can be particularly useful in the detection of explosive chemical warfare agents, as well as other substances, even at the smallest concentrations.

Table 1. General applications of ceramics/dendritic polymer composites.

\begin{tabular}{|c|c|c|}
\hline Dendritic Polymer-Ceramic & Application & Reference \\
\hline $\mathrm{PPI}-\mathrm{SiO}_{2}$ & Electrochemical (Redox-Active Materials) & [65] \\
\hline PAPAM-PDMS & High-Resolution Contact Printing & [68] \\
\hline Benzyl-Terminated Dendrons-SiO 2 & High-Resolution Capillary Gas Chromatography & {$[82]$} \\
\hline Benzyl-Terminated Dendrons-SiO 2 & Capillary microextraction & {$[83]$} \\
\hline L-glutamic acid-Chiral-Dendrimers-SiO 2 & HPLC & {$[90]$} \\
\hline PAMAM-SiO 2 & Photoluminescence Sensors & [91] \\
\hline PAMAM- $\mathrm{TiO}_{2}$ & $\mathrm{TiO}_{2}$ Nanoparticle Stabilization & [92] \\
\hline PAMAM-SiO 2 & Size Exclusion Chromatography & [108] \\
\hline Melamine Dendrons- $\mathrm{Al}_{2} \mathrm{O}_{3}$ & Polarity-Based Separation & [130] \\
\hline PAMAMOS & Electronics, Photonics, Magnetics, Sensors, Coatings & [133-135] \\
\hline
\end{tabular}

Moreover, these metal organoceramic nanocomposites are noteworthy candidates for catalysis reactions [171-173] (Table 2). They are particularly useful when gas phases are involved in reactions such as low molecular hydrocarbon hydrogenation and epoxidation. Ceramics may act not only as solid supports but also local reactant concentration enhancers, mostly through electrostatic attractions. Moreover, when both components exhibit photocatalytic properties, an enhanced performance is achieved. In some cases, the incorporation of the dendritic polymers increases the porosity of the inorganic supports to the point that they approximate the kinetics of homogenous catalysis. The same phenomenon occurs when inorganic nanoparticles are coated by dendrons. Concurrently, they allow easy and rapid retrieval regeneration and reuse.

Table 2. Applications of ceramics/dendritic polymer composites in catalysis.

\begin{tabular}{|c|c|c|}
\hline Dendritic Polymer-Ceramic & Application & Reference \\
\hline $\mathrm{PEI}-\mathrm{SiO}_{2-} \mathrm{TiO}_{2}$ & Nitro-compounds Reduction & [29] \\
\hline CBS-SiO & Ethylene Polymerization & [79] \\
\hline Pyridylphenylene dendrons- $\mathrm{SiO}_{2}$ & Suzuki cross-coupling & [86] \\
\hline Chiral-PAMAM-SiO & Enantiomeric Reactions & [87] \\
\hline $\mathrm{DAB}-\mathrm{SiO}_{2}$ & Selective Hydrogenation & [88] \\
\hline PAMAM-SiO 2 & Alcohol Oxidation & [113] \\
\hline PAMAM-SiO 2 & Olefin Hydroformylation & [114-116] \\
\hline PAMAM-SiO 2 & Carbonylation & [117-119] \\
\hline PAMAM-SiO 2 & Hydroesterification & {$[120]$} \\
\hline PAMAM-SiO 2 & Heck reaction & [121] \\
\hline PAMAM-SiO 2 & Olefin Epoxidation & [122] \\
\hline PAMAM-SiO 2 & Enzymolysis & [123] \\
\hline PAMAM-SiO 2 & Benzyl Alcohol, Methylene Blue Oxidation, Nitrophenol Reduction & [149] \\
\hline $\mathrm{DAB}_{-} \mathrm{SiO}_{2}$ & Phenols Hydrogenation & [171] \\
\hline${\mathrm{PEI}-\mathrm{SiO}_{2}}_{2}$ & $\mathrm{CO}, \mathrm{NO}, \mathrm{CH}_{4}, \mathrm{C}_{3} \mathrm{H}_{6}, \mathrm{C}_{3} \mathrm{H}_{8}$ Oxidation & [172] \\
\hline PEI-SiO $2-\mathrm{CeO}_{2}$ & Nitrophenol Reduction & [173] \\
\hline
\end{tabular}

Besides, due to their antimicrobial attributes against a wide range of bacteria, viruses, fungi parasites and other microorganisms, they may serve as leather or textile disinfection purposes [150]. Decontamination devices may also benefit from the implementation of these ceramic-organic-metal ternary systems. Thanks to their combined adsorption (Table 3) and microbicide capacity, they can be used for water treatment processes. In contrast to other absorbents, they are immune to bacterial infections and, apart from absorbing toxic pollutants, they may provide in parallel a certain level of sterilization. 
Table 3. Adsorption properties of ceramics/dendritic polymer composites.

\begin{tabular}{|c|c|c|}
\hline Dendritic Polymer-Ceramic & Application & Reference \\
\hline DAB, PEI, PG- $\mathrm{Al}_{2} \mathrm{O}_{3}, \mathrm{TiO}_{2} \mathrm{SiC}$ & PAH, BTX, THM, MTBE, Pesticides & {$[58,59]$} \\
\hline $\mathrm{PEI}-\mathrm{Al}_{2} \mathrm{O}_{3}$ & $\mathrm{PAH}$ & [61] \\
\hline PAMAM-SiO 2 & $\mathrm{Fe}_{4}\left[\mathrm{Fe}(\mathrm{CN})_{6}\right]_{3}, \mathrm{Co}_{2}\left[\mathrm{Fe}(\mathrm{CN})_{6}\right]$ & [62] \\
\hline PAMAM-TiO 2 & $\mathrm{Cu}(\mathrm{II}), \mathrm{Ni}(\mathrm{II}), \mathrm{Cr}(\mathrm{III})$ & [67] \\
\hline $\mathrm{PAMAM}_{-} \mathrm{SiO}_{2}$ & $\operatorname{Hg}(\mathrm{II})$ & {$[80,109,110,112]$} \\
\hline $\mathrm{PPH}-\mathrm{SiO}_{2}$ & $\mathrm{CO}_{2}$ & [84] \\
\hline $\mathrm{PEI}-\mathrm{SiO}_{2}$ & $\mathrm{Cu}(\mathrm{II}), \mathrm{Zn}(\mathrm{II}), \mathrm{Cd}(\mathrm{II})$ & [85] \\
\hline PAMAM-SiO 2 & $\mathrm{Cu}(\mathrm{II})$ & [94] \\
\hline Melamine Dendrons-SiO 2 & Atrazine & [95] \\
\hline PAMAM-Dendrons-SiO 2 & Organic Dyes, Amphiphilic Surfactants & [97] \\
\hline $\mathrm{PAMAM}^{-\mathrm{SiO}_{2}}$ & $\mathrm{Zn}(\mathrm{II}), \mathrm{Co}(\mathrm{II})$ & [98] \\
\hline PAMAM-SiO 2 & $\mathrm{Mn}(\mathrm{II})$ & [99] \\
\hline $\mathrm{PAMAM}_{-} \mathrm{SiO}_{2}$ & $\mathrm{Ni}(\mathrm{II})$ & [100] \\
\hline PAMAM-SiO 2 & $\mathrm{Co}(\mathrm{II})$ & [101] \\
\hline PAMAM-SiO 2 & $\mathrm{Cd}(\mathrm{II})$ & {$[102,103]$} \\
\hline PAMAM-SiO 2 & $\mathrm{Fe}(\mathrm{III})$ & {$[103,104]$} \\
\hline $\mathrm{PAMAM}_{-} \mathrm{SiO}_{2}$ & $\mathrm{~Pb}(\mathrm{II})$ & [105] \\
\hline $\mathrm{PAMAM}_{-} \mathrm{SiO}_{2}$ & $\mathrm{U}(\mathrm{IV})$ & [106] \\
\hline $\mathrm{PAMAM}_{-} \mathrm{SiO}_{2}$ & $\operatorname{Ag}(\mathrm{I})$ & {$[111,112]$} \\
\hline $\mathrm{PEI}-\mathrm{SiO}_{2}$ & $\mathrm{CO}_{2}$ & {$[125,126]$} \\
\hline TREN-SiO 2 & $\mathrm{CO}_{2}$ & [129] \\
\hline $\mathrm{PEI}-\mathrm{SiO}_{2}$ & $\mathrm{PAH}, \mathrm{Pb}(\mathrm{II}), \mathrm{Hg}(\mathrm{II}), \mathrm{Cd}(\mathrm{II}), \mathrm{Cr}(\mathrm{VI})$ & [148] \\
\hline
\end{tabular}

Another compelling aspect of dendro-ceramics is that they can be employed in nanomedicine (Table 4) as controlled DNA expression vehicles, emulating the modularity model that viruses follow in order to target distinct regions of the cell [174,175]. Silica nanoparticles modified by aminopropyltriethoxysilane (APES) and methyl triethoxysilane (MTES) can generate ternary complexes with DNA and dendrimers. The dense configuration of silica nanoparticles accelerates DNA accumulation into the surface of the cells and subsequent DNA endosomal-lysomal uptake, leading to better cell transfection levels. A biogenic silica system produced by a complex of DNA and a dendrimer bearing an amino group could simplify the formation of the silica nanoparticles and optimize the overall transfection process, as long as this ternary complex remains non-toxic.

Table 4. Ceramics/dendritic polymer composites applications in nanomedicine.

\begin{tabular}{|c|c|c|}
\hline Dendritic Polymer-Ceramic & Application & Reference \\
\hline PEI-HA & Hydroxy apatite formation & [30] \\
\hline $\mathrm{PAMAM}_{-} \mathrm{SiO}_{2}$ & Gene therapy & [63] \\
\hline PAMAM, CBS-SiO 2 & Antibacterials & {$[77]$} \\
\hline $\mathrm{CBS}-\mathrm{SiO}_{2}$ & Oligonucleotide Delivery Carriers & [78] \\
\hline PAMAM-SiO 2 & Fluorescence Imaging & [81] \\
\hline $\mathrm{PPH}-\mathrm{SiO}_{2}$ & Antibacterials & [89] \\
\hline PAMAM-SiO 2 & Anticancer Photothermal Therapy & [124] \\
\hline $\mathrm{PEI}-\mathrm{SiO}_{2}$ & Orthopedic Implants & [138] \\
\hline PEI-SiO 2 & Antibacterials & [150] \\
\hline PAMAM-HA & Hemoglobin Aquasomes & [156] \\
\hline $\mathrm{PAMAM}_{-} \mathrm{SiO}_{2}$ & Gene transfection & [175] \\
\hline
\end{tabular}

Last but not least, drug delivery systems based on hybrid ceramics bearing dendritic polymers is a hot topic as well (Table 5). There is an established potential for controlled protracted and stimuli triggered release as well as targeted therapy [176]. Shortcomings of dendritic polymer carriers are mainly an undesired response by the immune system [177], rapid clearance from blood circulation due to small size [178] and toxicity of cationic high Mw species [179]. They may be addressed by charge neutralization and magnification, 
resulting in the combination with silica. On the other side, there are biocompatibility issues on silica nanoparticle forms, such as toxicity due to aggregation or hemolytic activity. These are alleviated either by the formation of the composites or by additional coating by a biocompatible polymer [64].

Table 5. Applications of ceramics/dendritic polymer composites in drug delivery.

\begin{tabular}{|c|c|c|}
\hline Dendritic Polymer-Ceramic & Application & Reference \\
\hline $\mathrm{PAMAM}_{-} \mathrm{SiO}_{2}$ & Doxorubicin, Curcumin & [64] \\
\hline $\mathrm{DAB}_{-} \mathrm{SiO}_{2}$ & Ibuprofen & [74] \\
\hline $\mathrm{DAB}-\mathrm{SiO}_{2}$ & Levofloxacin & [75] \\
\hline $\mathrm{DAB}-\mathrm{SiO}_{2}$ & Redox-responsive release & [76] \\
\hline PAMAM-SiO 2 & Curcumin & [81] \\
\hline PAMAM-SiO 2 & Doxorubicin and $\mathrm{Bcl}-2$ targeted siRNA & [124] \\
\hline
\end{tabular}

Author Contributions: Conceptualization, M.A.; Data Curation, M.D., E.N., and T.K.; Formal analysis, M.D., E.N., and T.K.; Scientific Literature Investigation, M.D., E.N., and T.K.; Methodology, M.A. and M.D.; Project administration, M.D. and M.V.; Resources, M.A., M.D., E.N. and T.K.; Supervision, M.A.; Visualization, M.D., E.N., and T.K.; Writing—original draft, M.D.; Writing-review and editing, M.A., M.D., and M.V.; Funding Acquisition, M.A., E.N., and M.V. All authors have read and agreed to the published version of the manuscript.

Funding: This work was co-financed by Greece/Greek General Secretariat for Research and Technology and European Union under the frame of EPAnEK 2014-2020 Operational Programme Competitiveness, Entrepreneurship Innovation, project "MEDNANOLEAT" grant number T6rBП-00081.

Conflicts of Interest: The authors declare no conflict of interest.

\section{References}

1. Camargo, P.H.C.; Satyanarayana, K.G.; Wypych, F. Nanocomposites: Synthesis, structure, properties and new application opportunities. Mater. Res. 2009, 12, 1-39. [CrossRef]

2. Parveen, S.; Misra, R.; Sahoo, S.K. Nanoparticles: A boon to drug delivery, therapeutics, diagnostics and imaging. Nanomed. Nanotechnol. Biol. Med. 2012, 8, 147-166. [CrossRef] [PubMed]

3. Khan, I.; Saeed, K.; Khan, I. Nanoparticles: Properties, applications and toxicities. Arab. J. Chem. 2019, 12, 908-931. [CrossRef]

4. Niihara, K. New design concept of structural ceramics. Ceramic nanocomposites. J. Ceram. Soc. Jpn. Int. Ed. 1991, 99, 945-952. [CrossRef]

5. Kiani, A.; Rahmani, M.; Sivakumar, M.; Tan, B. Nanoceramics: Synthesis, characterization, and applications. J. Nanomater. 2014, 2014. [CrossRef]

6. Thomas, S.; Harshita, B.S.P.; Mishra, P.; Talegaonkar, S. Ceramic Nanoparticles: Fabrication Methods and Applications in Drug Delivery. Curr. Pharm. Des. 2015, 21, 6165-6188. [CrossRef]

7. Meulenberg, W.A.; Schulze-Küppers, F.; Deibert, W.; Gestel, T.V.; Baumann, S. Ceramic Membranes: Materials-ComponentsPotential Applications. ChemBioEng Rev. 2019, 6, 198-208. [CrossRef]

8. Benfer, S.; Árki, P.; Tomandl, G. Ceramic membranes for filtration applications_-Preparation and characterization. Adv. Eng. Mater. 2004, 6, 495-500. [CrossRef]

9. Acharya, M.; Foley, H.C. Spray-coating of nanoporous carbon membranes for air separation. J. Membr. Sci. 1999, 161, 1-5. [CrossRef]

10. de Lange, R.S.A.; Keizer, K.; Burggraaf, A.J. Analysis and theory of gas transport in microporous sol-gel derived ceramic membranes. J. Membr. Sci. 1995, 104, 81-100. [CrossRef]

11. Montanaro, L.; Saracco, G. Influence of some precursors on the physico-chemical characteristics of transition aluminas for the preparation of ceramic catalytic filters. Ceram. Int. 1995, 21, 43-49. [CrossRef]

12. Bodzek, M.; Konieczny, K. Comparison of ceramic and capillary membranes in the treatment of natural water by means of ultrafiltration and microfiltration. Desalination 1998, 119, 191-197. [CrossRef]

13. Bodzek, M.; Konieczny, K.; Rajca, M. Membranes in water and wastewater disinfection-Review. Arch. Environ. Prot. 2019, 45, 3-18. [CrossRef]

14. Russo, C. A new membrane process for the selective fractionation and total recovery of polyphenols, water and organic substances from vegetation waters (VW). J. Membr. Sci. 2007, 288, 239-246. [CrossRef]

15. Wang, P.; Xu, N.; Shi, J. A pilot study of the treatment of waste rolling emulsion using zirconia microfiltration membranes. J. Membr. Sci. 2000, 173, 159-166. [CrossRef] 
16. Yang, C.; Zhang, G.; Xu, N.; Shi, J. Preparation and application in oil-water separation of $\mathrm{ZrO}_{2} / \alpha-\mathrm{Al}_{2} \mathrm{O}_{3} \mathrm{MF}^{\mathrm{memb}} \mathrm{mane}$. J. Membr. Sci. 1998, 142, 235-243. [CrossRef]

17. Nair, P.; Mizukami, F.; Okubo, T.; Nair, J.; Keizer, K.; Burggraaf, A.J. High-temperature catalyst supports and ceramic membranes: Metastability and particle packing. AIChE J. 1997, 43, 2710-2714. [CrossRef]

18. Komolikov, Y.I.; Blaginina, L.A. Technology of ceramic ultrafiltration membranes. Ogneup. Tekhnicheskaya Keram. 2002, 43, 20-28.

19. Koo, O.M.; Rubinstein, I.; Onyuksel, H. Role of nanotechnology in targeted drug delivery and imaging: A concise review. Nanomed. Nanotechnol. Biol. Med. 2005, 1, 193-212. [CrossRef]

20. Moreno-Vega, A.I.; Gómez-Quintero, T.; Nuñez-Anita, R.E.; Acosta-Torres, L.S.; Castaño, V. Polymeric and ceramic nanoparticles in biomedical applications. J. Nanotechnol. 2012, 2012. [CrossRef]

21. Manzano, M.; Vallet-Regí, M. Mesoporous Silica Nanoparticles for Drug Delivery. Adv. Funct. Mater. 2020, 30, 3-5. [CrossRef]

22. Croissant, J.G.; Fatieiev, Y.; Almalik, A.; Khashab, N.M. Mesoporous Silica and Organosilica Nanoparticles: Physical Chemistry, Biosafety, Delivery Strategies, and Biomedical Applications. Adv. Healthc. Mater. 2018, 7, 1700831. [CrossRef] [PubMed]

23. Castillo, R.R.; Vallet-Regí, M. Functional mesoporous silica nanocomposites: Biomedical applications and biosafety. Int. J. Mol. Sci. 2019, 20, 929. [CrossRef] [PubMed]

24. Li, Z.; Mu, Y.; Peng, C.; Lavin, M.F.; Shao, H.; Du, Z. Understanding the mechanisms of silica nanoparticles for nanomedicine. Wiley Interdiscip. Rev. Nanomed. Nanobiotechnol. 2020, 13, e1658. [CrossRef]

25. Tang, F.; Li, L.; Chen, D. Mesoporous silica nanoparticles: Synthesis, biocompatibility and drug delivery. Adv. Mater. 2012, 24, 1504-1534. [CrossRef]

26. Croissant, J.G.; Fatieiev, Y.; Khashab, N.M. Degradability and Clearance of Silicon, Organosilica, Silsesquioxane, Silica Mixed Oxide, and Mesoporous Silica Nanoparticles. Adv. Mater. 2017, 29. [CrossRef]

27. Singh, D.; Singh, S.; Sahu, J.; Srivastava, S.; Singh, M.R. Ceramic nanoparticles: Recompense, cellular uptake and toxicity concerns. Artif. Cells Nanomed. Biotechnol. 2016, 44, 401-409. [CrossRef]

28. Vakifahmetoglu, C.; Zeydanli, D.; Colombo, P. Porous polymer derived ceramics. Mater. Sci. Eng. R 2016, 106, 1-30. [CrossRef]

29. Kitsou, I.; Panagopoulos, P.; Maggos, T.; Arkas, M.; Tsetsekou, A. Development of $\mathrm{SiO}_{2} @ \mathrm{TiO}_{2}$ core-shell nanospheres for catalytic applications. Appl. Surf. Sci. 2018, 441, 223-231. [CrossRef]

30. Tsiourvas, D.; Tsetsekou, A.; Arkas, M.; Diplas, S.; Mastrogianni, E. Covalent attachment of a bioactive hyperbranched polymeric layer to titanium surface for the biomimetic growth of calcium phosphates. J. Mater. Sci. Mater. Med. 2011, 22, 85-96. [CrossRef]

31. Vallet-Regí, M.; Ruiz-Hernández, E. Bioceramics: From bone regeneration to cancer nanomedicine. Adv. Mater. 2011, 23, 5177-5218. [CrossRef] [PubMed]

32. El-Ghannam, A. Bone reconstruction: From bioceramics to tissue engineering. Expert Rev. Med. Devices 2005, 2, 87-101. [CrossRef] [PubMed]

33. Habraken, W.J.E.M.; Wolke, J.G.C.; Jansen, J.A. Ceramic composites as matrices and scaffolds for drug delivery in tissue engineering. Adv. Drug Deliv. Rev. 2007, 59, 234-248. [CrossRef] [PubMed]

34. Vallet-Regí, M.; Salinas, A.J. Ceramics as Bone Repair Materials, 2nd ed.; Elsevier Ltd.: Amsterdam, The Netherlands, 2019; ISBN 9780081024515.

35. Tomalia, D.A.; Fréchet, J.M.J. Discovery of dendrimers and dendritic polymers: A brief historical perspective. J. Polym. Sci. Part A Polym. Chem. 2002, 40, 2719-2728. [CrossRef]

36. Fréchet, J.M.J.; Tomalia, D.A. (Eds.) Dendrimers and Other Dendritic Polymers; John Wiley \& Sons, Ltd.: Chichester, UK, 2001; ISBN 9780470845820.

37. Jaymand, M.; Lotfi, M.; Lotfi, R. Functional dendritic compounds: Potential prospective candidates for dental restorative materials and: In situ re-mineralization of human tooth enamel. RSC Adv. 2016, 6, 43127-43146. [CrossRef]

38. Svenson, S.; Tomalia, D.A. Dendrimers in biomedical applications-reflections on the field. Adv. Drug Deliv. Rev. 2012, 64, 102-115. [CrossRef]

39. Sheikhpour, M.; Barani, L.; Kasaeian, A. Biomimetics in drug delivery systems: A critical review. J. Control. Release 2017, 253, 97-109. [CrossRef]

40. Leiro, V.; Moreno, P.M.; Sarmento, B.; Durão, J.; Gales, L.; Pêgo, A.P.; Barrias, C.C. Design and Preparation of Biomimetic and Bioinspired Materials; Elsevier Ltd.: Amsterdam, The Netherlands, 2017; ISBN 9780081007464.

41. Fruchon, S.; Poupot, R. Pro-inflammatory versus anti-inflammatory effects of dendrimers: The two faces of immuno-modulatory nanoparticles. Nanomaterials 2017, 7, 251. [CrossRef]

42. Fan, Y.; Sun, W.; Shi, X. Design and Biomedical Applications of Poly(amidoamine)-Dendrimer-Based Hybrid Nanoarchitectures. Small Methods 2017, 1, 1700224. [CrossRef]

43. Yetisgin, A.A.; Cetinel, S.; Zuvin, M.; Kosar, A.; Kutlu, O. Therapeutic Nanoparticles and Their Targeted Delivery Applications. Molecules 2020, 25, 2193. [CrossRef]

44. Le, N.T.T.; Nguyen, T.N.Q.; Cao, V.D.; Hoang, D.T.; Ngo, V.C.; Thi, T.T.H. Recent progress and advances of multi-stimuliresponsive dendrimers in drug delivery for cancer treatment. Pharmaceutics 2019, 11, 591. [CrossRef] [PubMed]

45. Devnarain, N.; Osman, N.; Fasiku, V.O.; Makhathini, S.; Salih, M.; Ibrahim, U.H.; Govender, T. Intrinsic stimuli-responsive nanocarriers for smart drug delivery of antibacterial agents-An in-depth review of the last two decades. Wiley Interdiscip. Rev. Nanomed. Nanobiotechnol. 2020, 13, e1664. [CrossRef] [PubMed] 
46. Majumder, J.; Minko, T. Multifunctional and stimuli-responsive nanocarriers for targeted therapeutic delivery. Expert Opin. Drug Deliv. 2020, 1-23. [CrossRef]

47. Saravanakumar, K.; Hu, X.; Ali, D.M.; Wang, M.-H. Emerging Strategies in Stimuli-Responsive Nanocarriers as the Drug Delivery System for Enhanced Cancer Therapy. Curr. Pharm. Des. 2019, 25, 2609-2625. [CrossRef] [PubMed]

48. Shukla, R.; Singh, A.; Pardhi, V.; Sunil Dubey, P.K. Dendrimer (polyamidoamine, polypropylene imine, poly-L-lysine, carbosilane dendrimers, triazine dendrimers) as promising tool for anticancer therapeutics. In Polymeric Nanoparticles as a Promising Tool for Anti-Cancer Therapeutics; Wolff, A.G., Ed.; Elsevier Ltd.: Amsterdam, The Netherlands, 2019; pp. 233-255, ISBN 9780128169636.

49. Wang, B.Y.; Liao, M.L.; Hong, G.C.; Chang, W.W.; Chu, C.C. Near-Infrared-Triggered photodynamic therapy toward breast cancer cells using Dendrimer-Functionalized upconversion nanoparticles. Nanomaterials 2017, 7, 269. [CrossRef] [PubMed]

50. Shahbazi-Gahrouei, D.; Khaniabadi, P.; Khaniabadi, B.; Shahbazi-Gahrouei, S. Medical imaging modalities using nanoprobes for cancer diagnosis: A literature review on recent findings. J. Res. Med. Sci. 2019, 24, 38. [CrossRef] [PubMed]

51. Shi, X.; Wang, S.H.; Van Antwerp, M.E.; Chen, X.; Baker, J.R. Targeting and detecting cancer cells using spontaneously formed multifunctional dendrimer-stabilized gold nanoparticles. Analyst 2009, 134, 1373-1379. [CrossRef] [PubMed]

52. Li, H.; Sun, J.; Zhu, H.; Wu, H.; Zhang, H.; Gu, Z.; Luo, K. Recent advances in development of dendriticpolymer-based nanomedicines for cancer diagnosis. Wiley Interdiscip. Rev. Nanomed. Nanobiotechnol. 2020, e1670. [CrossRef]

53. El Kadib, A.; Katir, N.; Bousmina, M.; Majoral, J.P. Dendrimer-silica hybrid mesoporous materials. New J. Chem. 2012, 36, 241-255. [CrossRef]

54. Gaikwad, A.V.; Boffa, V.; ten Elshof, J.E.; Rothenberg, G. Cat-in-a-Cup: Facile Separation of Large Homogeneous Catalysts. Angew. Chem. 2008, 120, 5487-5490. [CrossRef]

55. Safari, J.; Zarnegar, Z.; Sadeghi, M.; Enayati-Najafabadi, A. Dendritic macromolecules supported Ag nanoparticles as efficient catalyst for the reduction of 4-nitrophenol. J. Mol. Struct. 2016, 1125, 772-776. [CrossRef]

56. Arkas, M.; Tsiourvas, D.; Paleos, C.M. Organosilicon dendritic networks in porous ceramics for water purification. Chem. Mater. 2005, 17, 3439-3444. [CrossRef]

57. Arkas, M.; Tsiourvas, D.; Paleos, C.M. Functional dendritic polymers for the development of hybrid materials for water purification. Macromol. Mater. Eng. 2010, 295, 883-898. [CrossRef]

58. Arkas, M.; Allabashi, R.; Tsiourvas, D.; Mattausch, E.M.; Perfler, R. Organic/inorganic hybrid filters based on dendritic and cyclodextrin "nanosponges" for the removal of organic pollutants from water. Environ. Sci. Technol. 2006, 40, $2771-2777$. [CrossRef]

59. Allabashi, R.; Arkas, M.; Hörmann, G.; Tsiourvas, D. Removal of some organic pollutants in water employing ceramic membranes impregnated with cross-linked silylated dendritic and cyclodextrin polymers. Water Res. 2007, 41, 476-486. [CrossRef] [PubMed]

60. Zhang, G.; Qin, Y.; Zhang, H.; Shang, Y.; Sun, M.; Liu, B.; Li, Z. Electronic structure-transport property relationships of polyferrocenylene, polyferrocenylacetylene, and polyferrocenylsilane. J. Phys. Chem. C 2010, 114, 9469-9477. [CrossRef]

61. Tsetsekou, A.; Arkas, M.; Kritikaki, A.; Simonetis, S.; Tsiourvas, D. Optimization of hybrid hyperbranched polymer/ceramic filters for the efficient absorption of polyaromatic hydrocarbons from water. J. Membr. Sci. 2008, 311, 128-135. [CrossRef]

62. Zamponi, S.; Kijak, A.M.; Sommer, A.J.; Marassi, R.; Kulesza, P.J.; Cox, J.A. Electrochemistry of Prussian Blue in silica sol-gel electrolytes doped with polyamidoamine dendrimers. J. Solid State Electrochem. 2002, 6, 528-533. [CrossRef]

63. Ainalem, M.L.; Campbell, R.A.; Nylander, T. Interactions between DNA and poly(amido amine) dendrimers on Silica surfaces. Langmuir 2010, 26, 8625-8635. [CrossRef]

64. Xu, X.; Lü, S.; Gao, C.; Bai, X.; Feng, C.; Gao, N.; Liu, M. Multifunctional drug carriers comprised of mesoporous silica nanoparticles and polyamidoamine dendrimers based on layer-by-layer assembly. Mater. Des. 2015, 88, 1127-1133. [CrossRef]

65. Díaz, I.; García, B.; Alonso, B.; Casado, C.M.; Morán, M.; Losada, J.; Pérez-Pariente, J. Ferrocenyl dendrimers incorporated into mesoporous silica: New hybrid redox-active materials. Chem. Mater. 2003, 15, 1073-1079. [CrossRef]

66. Arkas, M.; Tsiourvas, D.; Paleos, C.M. Functional dendrimeric "Nanosponges" for the removal of polycyclic aromatic hydrocarbons from water. Chem. Mater. 2003, 15, 2844-2847. [CrossRef]

67. Barakat, M.A.; Ramadan, M.H.; Alghamdi, M.A.; Algarny, S.S.; Woodcock, H.L.; Kuhn, J.N. Remediation of Cu(II), Ni(II), and $\mathrm{Cr}(\mathrm{III})$ ions from simulated wastewater by dendrimer/titania composites. J. Environ. Manag. 2013, 117, 50-57. [CrossRef] [PubMed]

68. Li, H.; Kang, D.J.; Blamire, M.G.; Huck, W.T.S. High-Resolution Contact Printing with Dendrimers. Nano Lett. 2002, 2, 347-349. [CrossRef]

69. Esumi, K.; Goino, M. Adsorption of poly(amidoamine) dendrimers on alumina/water and silica/water interfaces. Langmuir 1998, 14, 4466-4470. [CrossRef]

70. Tokarczyk, K.; Jachimska, B. Quantitative interpretation of PAMAM dendrimers adsorption on silica surface. J. Colloid Interface Sci. 2017, 503, 86-94. [CrossRef]

71. Ottaviani, M.F.; Turro, N.J.; Jockusch, S.; Tomalia, D.A. EPR investigation of the adsorption of dendrimers on porous surfaces. J. Phys. Chem. B 2003, 107, 2046-2053. [CrossRef]

72. Fu, S.; Zhu, M.; Zhu, Y. Organosilicon polymer-derived ceramics: An overview. J. Adv. Ceram. 2019, 8, 457-478. [CrossRef]

73. Ottenbrite, R.M.; Yin, R.; Zengin, H.; Suzuki, K.; Siddiqui, J.A. Surface Modification of Silica Particles and Silica Glass Beads Polymer Surface Modification of Particles. Spec. Monomers Polym. 2000, 13, 170-183. 
74. González, B.; Colilla, M.; De Laorden, C.L.; Vallet-Regí, M. A novel synthetic strategy for covalently bonding dendrimers to ordered mesoporous silica: Potential drug delivery applications. J. Mater. Chem. 2009, 19, 9012-9024. [CrossRef]

75. González, B.; Colilla, M.; Díez, J.; Pedraza, D.; Guembe, M.; Izquierdo-Barba, I.; Vallet-Regí, M. Mesoporous silica nanoparticles decorated with polycationic dendrimers for infection treatment. Acta Biomater. 2018, 68, 261-271. [CrossRef] [PubMed]

76. Nadrah, P.; Porta, F.; Planinšek, O.; Kros, A.; Gaberšček, M. Poly(propylene imine) dendrimer caps on mesoporous silica nanoparticles for redox-responsive release: Smaller is better. Phys. Chem. Chem. Phys. 2013, 15, 10740-10748. [CrossRef] [PubMed]

77. Sánchez-Milla, M.; Gómez, R.; Pérez-Serrano, J.; Sánchez-Nieves, J.; de la Mata, F.J. Functionalization of silica with amine and ammonium alkyl chains, dendrons and dendrimers: Synthesis and antibacterial properties. Mater. Sci. Eng. C 2020, $109,110526$. [CrossRef] [PubMed]

78. Martínez, Á.; Fuentes-Paniagua, E.; Baeza, A.; Sánchez-Nieves, J.; Cicuéndez, M.; Gõmez, R.; De La Mata, F.J.; González, B.; Vallet-Regí, M. Mesoporous Silica Nanoparticles Decorated with Carbosilane Dendrons as New Non-viral Oligonucleotide Delivery Carriers. Chem.-A Eur. J. 2015, 21, 15651-15666. [CrossRef]

79. Andrés, R.; Jesús, E.D.; Fierro, J.L.G.; Terreros, P. Bifunctional carbosilane dendrons for the immobilization of zirconocene catalysts on silica. New, J. Chem. 2011, 35, 2203-2211. [CrossRef]

80. Sun, X.; Qu, R.; Sun, C.; Zhang, Y.; Sun, S.; Ji, C.; Yin, P. Sol-gel preparation and Hg(II) adsorption properties of silica-gel supported low generation polyamidoamine dendrimers polymer adsorbents. Ind. Eng. Chem. Res. 2014, 53, 2878-2888. [CrossRef]

81. Xu, X.; Lü, S.; Gao, C.; Wang, X.; Bai, X.; Gao, N.; Liu, M. Facile preparation of pH-sensitive and self-fluorescent mesoporous silica nanoparticles modified with PAMAM dendrimers for label-free imaging and drug delivery. Chem. Eng. J. 2015, 266, 171-178. [CrossRef]

82. Newkome, G.R.; Yoo, K.S.; Kabir, A.; Malik, A. Synthesis of benzyl-terminated dendrons for use in high-resolution capillary gas chromatography. Tetrahedron Lett. 2001, 42, 7537-7541. [CrossRef]

83. Kabir, A.; Hamlet, C.; Yoo, K.S.; Newkome, G.R.; Malik, A. Capillary microextraction on sol-gel dendrimer coatings. J. Chromatogr. A 2004, 1034, 1-11. [CrossRef]

84. Riegert, D.; Bareille, L.; Laurent, R.; Majoral, J.P.; Caminade, A.M.; Chaumonnot, A. Silica Functionalized by Bifunctional Dendrimers: Hybrid Nanomaterials for Trapping $\mathrm{CO}_{2}$. Eur. J. Inorg. Chem. 2016, 2016, 3103-3110. [CrossRef]

85. Pang, Y.; Zeng, G.; Tang, L.; Zhang, Y.; Liu, Y.; Lei, X.; Li, Z.; Zhang, J.; Xie, G. PEI-grafted magnetic porous powder for highly effective adsorption of heavy metal ions. Desalination 2011, 281, 278-284. [CrossRef]

86. Sorokina, S.A.; Kuchkina, N.V.; Lawson, B.P.; Krasnova, I.Y.; Nemygina, N.A.; Nikoshvili, L.Z.; Talanova, V.N.; Stein, B.D.; Pink, M.; Morgan, D.G.; et al. Pyridylphenylene dendrons immobilized on the surface of chemically modified magnetic silica as efficient stabilizing molecules of Pd species. Appl. Surf. Sci. 2019, 488, 865-873. [CrossRef]

87. Chung, Y.M.; Rhee, H.K. Silica-supported dendritic chiral auxiliaries for enantioselective addition of diethylzinc to benzaldehyde. Comptes Rendus Chim. 2003, 6, 695-705. [CrossRef]

88. Karakhanov, E.; Maximov, A.; Kardasheva, Y.; Semernina, V.; Zolotukhina, A.; Ivanov, A.; Abbott, G.; Rosenberg, E.; Vinokurov, V. Pd nanoparticles in dendrimers immobilized on silica-polyamine composites as catalysts for selective hydrogenation. ACS Appl. Mater. Interfaces 2014, 6, 8807-8816. [CrossRef]

89. Hameau, A.; Collière, V.; Grimoud, J.; Fau, P.; Roques, C.; Caminade, A.-M.; Turrin, C.-O. PPH dendrimers grafted on silica nanoparticles: Surface chemistry, characterization, silver colloids hosting and antibacterial activity. RSC Adv. 2013, 3, 19015. [CrossRef]

90. Mathews, B.T.; Beezer, A.E.; Snowden, M.J.; Hardy, M.J.; Mitchell, J.C. The synthesis of immobilised chiral dendrimers. New J. Chem. 2001, 25, 807-818. [CrossRef]

91. Gerrans, K.; Luhrs, A.; Feider, C.; Margerum, L.D. Silica nanoparticles functionalized with polyamidoamine (PAMAM) dendrimers as platforms for photoluminescence (PL) sensing of copper and cyanide ions. J. Colloid Interface Sci. 2016, 470, 276-283. [CrossRef]

92. Nakanishi, Y.; Imae, T. Preparation of siloxy focal dendron-protected $\mathrm{TiO}_{2}$ nanoparticles and their photocatalysis. J. Colloid Interface Sci. 2006, 297, 122-129. [CrossRef]

93. Pawlaczyk, M.; Pasieczna-Patkowska, S.; Ryczkowski, J.; Schroeder, G. Photoacoustic infrared spectroscopic studies of silica surface functionalized by dendrimers. Vib. Spectrosc. 2019, 103, 102943. [CrossRef]

94. Pawlaczyk, M.; Schroeder, G. Adsorption studies of $\mathrm{Cu}(\mathrm{II})$ ions on dendrimer-grafted silica-based materials. J. Mol. Liq. 2019, 281, 176-185. [CrossRef]

95. Acosta, E.J.; Gonzalez, S.O.; Simanek, E.E. Synthesis, characterization, and application of melamine-based dendrimers supported on silica gel. J. Polym. Sci. Part A Polym. Chem. 2005, 43, 168-177. [CrossRef]

96. Bu, J.; Li, R.; Quah, C.W.; Carpenter, K.J. Propagation of PAMAM dendrons on silica gel: A study on the reaction kinetics. Macromolecules 2004, 37, 6687-6694. [CrossRef]

97. Chu, C.C.; Ueno, N.; Imae, T. Solid-phase synthesis of amphiphilic dendron-surface-modified silica particles and their application toward water purification. Chem. Mater. 2008, 20, 2669-2676. [CrossRef]

98. Wu, K.; Luan, L.; Xing, J.X.; Ma, S.; Xue, Z.; Xu, W.; Niu, Y. Removal of Zn(II) and Co(II) from N,N-dimethylformamide by polyamidoamine dendrimers decorated silica: Performance and mechanism. J. Mol. Liq. 2020, 308, 113073. [CrossRef]

99. Fu, T.; Niu, Y.; Zhou, Y.; Wang, K.; Mu, Q.; Qu, R.; Chen, H.; Yuan, B.; Yang, H. Adsorption of Mn(II) from aqueous solution by silica-gel supported polyamidoamine dendrimers: Experimental and DFT study. J. Taiwan Inst. Chem. Eng. 2019, 97, 189-199. [CrossRef] 
100. Qiu, Z.; Niu, Y.; Fu, T.; Wang, K.; Mu, Q.; Wang, F. Removal of Ni(II) from fuel ethanol by PAMAM dendrimers/silica hybrid materials: Combined experimental and theoretical study. Chem. Eng. Res. Des. 2019, 144, 174-184. [CrossRef]

101. Song, X.; Niu, Y.; Zhang, P.; Zhang, C.; Zhang, Z.; Zhu, Y.; Qu, R. Removal of Co(II) from fuel ethanol by silica-gel supported PAMAM dendrimers: Combined experimental and theoretical study. Fuel 2017, 199, 91-101. [CrossRef]

102. Ren, B.; Wang, K.; Zhang, B.; Li, H.; Niu, Y.; Chen, H.; Yang, Z.; Li, X.; Zhang, H. Adsorption behavior of PAMAM dendrimers functionalized silica for Cd(II) from aqueous solution: Experimental and theoretical calculation. J. Taiwan Inst. Chem. Eng. 2019, 101, 80-91. [CrossRef]

103. Zhu, Y.; Niu, Y.; Li, H.; Ren, B.; Qu, R.; Chen, H.; Zhang, Y. Removal of Cd(II) and Fe(III) from DMSO by silica gel supported PAMAM dendrimers: Equilibrium, thermodynamics, kinetics and mechanism. Ecotoxicol. Environ. Saf. 2018, 162, 253-260. [CrossRef]

104. Zhang, S.; Niu, Y.; Chen, Z.; Chen, H.; Yang, Z.; Bai, L.; Yuan, B. Removal of Fe(III) from ethanol by silica-gel supported ester-terminated pamam dendrimers: Experimental and dft calculation. Desalin. Water Treat. 2019, 164, 310-318. [CrossRef]

105. Niu, Y.; Qu, R.; Sun, C.; Wang, C.; Chen, H.; Ji, C.; Zhang, Y.; Shao, X.; Bu, F. Adsorption of Pb(II) from aqueous solution by silica-gel supported hyperbranched polyamidoamine dendrimers. J. Hazard. Mater. 2013, 244-245, 276-286. [CrossRef]

106. Shaaban, A.F.; Khalil, A.A.; Lasheen, T.A.; Nouh, E.S.A.; Ammar, H. Polyamidoamine dendrimers modified silica gel for uranium(VI) removal from aqueous solution using batch and fixed-bed column methods. Desalin. Water Treat. 2018, 102, 197-210. [CrossRef]

107. Reynhardt, J.P.K.; Yang, Y.; Sayari, A.; Alper, H. Polyamidoamine dendrimers prepared Inside the channels of pore-expanded periodic mesoporous silica. Adv. Funct. Mater. 2005, 15, 1641-1646. [CrossRef]

108. Sakai, K.; Kunitake, M.; Teng, T.C.; Katada, A.; Harada, T.; Yoshida, K.; Yamanaka, K.; Asami, Y.; Sakata, M.; Hirayama, C. Designable Size Exclusion Chromatography Columns Based on Dendritic Polymer-Modified Porous Silica Particles. Chem. Mater. 2003, 15, 4091-4097. [CrossRef]

109. Niu, Y.; Qu, R.; Chen, H.; Mu, L.; Liu, X.; Wang, T.; Zhang, Y.; Sun, C. Synthesis of silica gel supported salicylaldehyde modified PAMAM dendrimers for the effective removal of $\mathrm{Hg}$ (II) from aqueous solution. J. Hazard. Mater. 2014, 278, 267-278. [CrossRef]

110. Niu, Y.; Yang, J.; Qu, R.; Gao, Y.; Du, N.; Chen, H.; Sun, C.; Wang, W. Synthesis of Silica-Gel-Supported Sulfur-Capped PAMAM Dendrimers for Efficient $\mathrm{Hg}$ (II) Adsorption: Experimental and DFT Study. Ind. Eng. Chem. Res. 2016, 55, 3679-3688. [CrossRef]

111. Zhang, P.; Niu, Y.; Qiao, W.; Xue, Z.; Bai, L.; Chen, H. Experimental and DFT investigation on the adsorption mechanism of silica gel supported sulfur-capped PAMAM dendrimers for Ag(I). J. Mol. Liq. 2018, 263, 390-398. [CrossRef]

112. Song, X.; Niu, Y.; Qiu, Z.; Zhang, Z.; Zhou, Y.; Zhao, J.; Chen, H. Adsorption of Hg(II) and Ag(I) from fuel ethanol by silica gel supported sulfur-containing PAMAM dendrimers: Kinetics, equilibrium and thermodynamics. Fuel 2017, 206, 80-88. [CrossRef]

113. Li, H.; Zheng, Z.; Cao, M.; Cao, R. Stable gold nanoparticle encapsulated in silica-dendrimers organic-inorganic hybrid composite as recyclable catalyst for oxidation of alcohol. Microporous Mesoporous Mater. 2010, 136, 42-49. [CrossRef]

114. Reynhardt, J.P.K.; Yang, Y.; Sayari, A.; Alper, H. Rhodium complexed C2-PAMAM dendrimers supported on large pore Davisil silica as catalysts for the hydroformylation of olefins. Adv. Synth. Catal. 2005, 347, 1379-1388. [CrossRef]

115. Bourque, S.C.; Alper, H.; Manzer, L.E.; Arya, P. Hydroformylation reactions using recyclable rhodium-complexed dendrimers on silica [4]. J. Am. Chem. Soc. 2000, 122, 956-957. [CrossRef]

116. Reynhardt, J.P.K.; Yang, Y.; Sayari, A.; Alper, H. Periodic mesoporous silica-supported recyclable rhodium-complexed dendrimer catalysts. Chem. Mater. 2004, 16, 4095-4102. [CrossRef]

117. Lu, S.M.; Alper, H. Intramolecular carbonylation reactions with recyclable palladium-complexed dendrimers on silica: Synthesis of oxygen, nitrogen, or sulfur-containing medium ring fused heterocycles. J. Am. Chem. Soc. 2005, 127, 14776-14784. [CrossRef] [PubMed]

118. Lu, S.M.; Alper, H. Synthesis of large ring macrocycles (12-18) by recyclable palladiumComplexed dendrimers on silica gel catalyzed intramolecular cyclocarbonylation reactions. Chem.-A Eur. J. 2007, 13, 5908-5916. [CrossRef] [PubMed]

119. Antebi, S.; Arya, P.; Manzer, L.E.; Alper, H. Carbonylation reactions of iodoarenes with PAMAM dendrimer-palladium catalysts immobilized on silica. J. Org. Chem. 2002, 67, 6623-6631. [CrossRef]

120. Reynhardt, J.P.K.; Alper, H. Hydroesterification Reactions with Palladium-Complexed PAMAM Dendrimers Immobilized on Silica. J. Org. Chem. 2003, 68, 8353-8360. [CrossRef]

121. Alper, H.; Arya, P.; Bourque, S.C.; Jefferson, G.R.; Manzer, L.E. Heck reaction using palladium complexed to dendrimers on silica. Can. J. Chem. 2000, 78, 920-924. [CrossRef]

122. Bu, J.; Judeh, Z.M.A.; Ching, C.B.; Kawi, S. Epoxidation of olefins catalyzed by Mn(II) salen complex anchored on PAMAM-SiO2 dendrimer. Catal. Lett. 2003, 85, 183-187. [CrossRef]

123. Wang, S.; Su, P.; Ding, F.; Yang, Y. Immobilization of cellulase on polyamidoamine dendrimer-grafted silica. J. Mol. Catal. B Enzym. 2013, 89, 35-40. [CrossRef]

124. Zhang, Q.; Wang, L.; Jiang, Y.; Gao, W.; Wang, Y.; Yang, X.; Yang, X.; Liu, Z. Gold Nanorods with Silica Shell and PAMAM Dendrimers for Efficient Photothermal Therapy and Low Toxic Codelivery of Anticancer Drug and siRNA. Adv. Mater. Interfaces 2017, 4, 1-9. [CrossRef]

125. Hicks, J.C.; Drese, J.H.; Fauth, D.J.; Gray, M.L.; Qi, G.; Jones, C.W. Designing adsorbents for $\mathrm{CO}_{2}$ capture from flue gashyperbranched aminosilicas capable of capturing $\mathrm{CO}_{2}$ reversibly. J. Am. Chem. Soc. 2008, 130, 2902-2903. [CrossRef] [PubMed] 
126. Drese, J.H.; Choi, S.; Lively, R.P.; Koros, W.J.; Fauth, D.J.; Gray, M.L.; Jones, C.W. Synthesis-structure-property relationships for Hyperbranched aminosilica $\mathrm{CO}_{2}$ adsorbents. Adv. Funct. Mater. 2009, 19, 3821-3832. [CrossRef]

127. López-Aranguren, P.; Vega, L.F.; Domingo, C. A new method using compressed $\mathrm{CO}_{2}$ for the in situ functionalization of mesoporous silica with hyperbranched polymers. Chem. Commun. 2013, 49, 11776-11778. [CrossRef]

128. Acosta, E.J.; Carr, C.S.; Simanek, E.E.; Shantz, D.F. Engineering nanospaces: Iterative synthesis of melamine-based dendrimers on amine-functionalized SBA-15 leading to complex hybrids with controllable chemistry and porosity. Adv. Mater. 2004, 16, 985-989. [CrossRef]

129. Bhagiyalakshmi, M.; Park, S.D.; Cha, W.S.; Jang, H.T. Development of TREN dendrimers over mesoporous SBA-15 for CO 2 adsorption. Appl. Surf. Sci. 2010, 256, 6660-6666. [CrossRef]

130. Yoo, S.; Yeu, S.; Sherman, R.L.; Simanek, E.E.; Shantz, D.F.; Ford, D.M. Reverse-selective membranes formed by dendrimers on mesoporous ceramic supports. J. Membr. Sci. 2009, 334, 16-22. [CrossRef]

131. Tsubokawa, N.; Hayashi, S.; Nishimura, J. Grafting of hyperbranched polymers onto ultrafine silica: Postgraft polymerization of vinyl monomers initiated by pendant azo groups of grafted polymer chains on the surface. Prog. Org. Coat. 2002, 44, 69-74. [CrossRef]

132. Hayashi, S.; Fujiki, K.; Tsubokawa, N. Grafting of hyperbranched polymers onto ultrafine silica: Postgraft polymerization of vinyl monomers initiated by pendant initiating groups of polymer chains grafted onto the surface. React. Funct. Polym. 2000, 46, 193-201. [CrossRef]

133. Dvornic, P.R. PAMAMOS: The first commercial silicon-containing dendrimers and their applications. J. Polym. Sci. Part A Polym. Chem. 2006, 44, 2755-2773. [CrossRef]

134. Dvornic, P.R.; Li, J.; De Leuze-Jallouli, A.M.; Reeves, S.D.; Owen, M.J. Nanostructured dendrimer-based networks with hydrophilic polyamidoamine and hydrophobic organosilicon domains. Macromolecules 2002, 35, 9323-9333. [CrossRef]

135. Chujo, Y.; Matsuki, H.; Kure, S.; Saegusa, T.; Yazawa, T. Control of pore size of porous silica by means of pyrolysis of an organic-inorganic polymer hybrid. J. Chem. Soc. Chem. Commun. 1994, 635-636. [CrossRef]

136. Tsiourvas, D.; Tsetsekou, A.; Papavasiliou, A.; Arkas, M.; Boukos, N. A novel hybrid sol-gel method for the synthesis of highly porous silica employing hyperbranched poly(ethyleneimine) as a reactive template. Microporous Mesoporous Mater. 2013, 175, 59-66. [CrossRef]

137. Turrin, C.O.; Maraval, V.; Caminade, A.M.; Majoral, J.P.; Mehdi, A.; Reyé, C. Organic-Inorganic hybrid materials incorporating phosphorus-containing dendrimers. Chem. Mater. 2000, 12, 3848-3856. [CrossRef]

138. Vardavoulias, M.; Gkomoza, E.; Tsetsekou, A.; Kitsou, I.; Arkas, M.; Papageorgiou, M.; González, S.M.S.; Cubillos, Y.L.; Cepas, V.; Jensen, H.E.; et al. Hydrogel and Xerogel Active Ingredient Carriers Made from Dendritic Polymers and Silica for Solid Substrate Coating Applications. Greek Patent Application Number 2019010000585, 30 December 2019.

139. Talham, D.R. Biomineralization: Principles and Concepts in Bioinorganic Materials Chemistry Stephen Mann. Oxford University Press, New York, 2001. Cryst. Growth Des. 2002, 2, 675. [CrossRef]

140. Sumper, M.; Brunner, E. Learning from diatoms: Nature's tools for the production of nanostructured silica. Adv. Funct. Mater. 2006, 16, 17-26. [CrossRef]

141. Lechner, C.C.; Becker, C.F.W. Silaffins in silica biomineralization and biomimetic silica precipitation. Mar. Drugs 2015, 13, 5297-5333. [CrossRef] [PubMed]

142. Knecht, M.R.; Wright, D.W. Amine-terminated dendrimers as biomimetic templates for silica nanosphere formation. Langmuir 2004, 20, 4728-4732. [CrossRef] [PubMed]

143. Knecht, M.R.; Sewell, S.L.; Wright, D.W. Size control of dendrimer-templated silica. Langmuir 2005, 21, 2058-2061. [CrossRef]

144. Coradin, T.; Durupthy, O.; Livage, J. Interactions of amino-containing peptides with sodium silicate and colloidal silica: A biomimetic approach of silicification. Langmuir 2002, 18, 2331-2336. [CrossRef]

145. Kobler, J.; Möller, K.; Bein, T. Colloidal Suspensions of Functionalized Mesoporous Silica Nanoparticles. ACS Nano 2008, 2, 791-799. [CrossRef] [PubMed]

146. Petrakli, F.; Arkas, M.; Tsetsekou, A. $\alpha$-Alumina nanospheres from nano-dispersed boehmite synthesized by a wet chemical route. J. Am. Ceram. Soc. 2018, 101, 3508-3519. [CrossRef]

147. Zhang, F.; Yang, S.P.; Wang, W.M.; Chen, H.M.; Wang, Z.H.; Yu, X. Bin Preparation of nanocrystalline ceramic oxide powders in the presence of anionic starburst dendrimer. Mater. Lett. 2004, 58, 3285-3289. [CrossRef]

148. Arkas, M.; Tsiourvas, D. Organic/inorganic hybrid nanospheres based on hyperbranched poly(ethylene imine) encapsulated into silica for the sorption of toxic metal ions and polycyclic aromatic hydrocarbons from water. J. Hazard. Mater. 2009, 170, 35-42. [CrossRef] [PubMed]

149. Nemanashi-Maumela, M.; Nongwe, I.; Motene, R.C.; Davids, B.L.; Meijboom, R. Au and Ag nanoparticles encapsulated within silica nanospheres using dendrimers as dual templating agent and their catalytic activity. Mol. Catal. 2017, 438, 184-196. [CrossRef]

150. Arkas, M.; Kithreoti, G.; Boukos, N.; Kitsou, I.; Petrakli, F.; Panagiotaki, K. Two completely different biomimetic reactions mediated by the same matrix producing inorganic/organic/inorganic hybrid nanoparticles. Nano-Struct. Nano-Objects 2018, 14, 138-148. [CrossRef]

151. Kröger, N.; Deutzmann, R.; Bergsdorf, C.; Sumper, M. Species-specific polyamines from diatoms control silica morphology. Proc. Natl. Acad. Sci. USA 2000, 97, 14133-14138. [CrossRef] 
152. Mizutani, T.; Nagase, H.; Fujiwara, N.; Ogoshi, H. Silicic Acid Polymerization Catalyzed by Amines and Polyamines. Bull. Chem. Soc. Jpn. 1998, 71, 2017-2022. [CrossRef]

153. Knecht, M.R.; Wright, D.W. Functional analysis of the biomimetic silica precipitating activity of the R5 peptide from Cylindrotheca fusiformis. Chem. Commun. 2003, 3, 3038-3039. [CrossRef]

154. Kossovsky, N.; Gelman, A.; Sponsler, E.E.; Hnatyszyn, H.J.; Rajguru, S.; Torres, M.; Pham, M.; Crowder, J.; Zemanovich, J.; Chung, A.; et al. Surface-modified nanocrystalline ceramics for drug delivery applications. Biomaterials 1994, 15, 1201-1207. [CrossRef]

155. Kossovsky, N.; Gelman, A.; Rajguru, S.; Nguyen, R.; Sponsler, E.; Hnatyszyn, H.J.; Chow, K.; Chung, A.; Torres, M.; Zemanovich, J.; et al. Control of molecular polymorphisms by a structured carbohydrate/ceramic delivery vehicle-Aquasomes. J. Control. Release 1996, 39, 383-388. [CrossRef]

156. Khopade, A.J.; Khopade, S.; Jain, N.K. Development of hemoglobin aquasomes from spherical hydroxyapatite cores precipitated in the presence of half-generation poly(amidoamine) dendrimer. Int. J. Pharm. 2002, 241, 145-154. [CrossRef]

157. Zhang, F.; Zhou, Z.H.; Yang, S.P.; Mao, L.H.; Chen, H.M.; Yu, X. Bin Hydrothermal synthesis of hydroxyapatite nanorods in the presence of anionic starburst dendrimer. Mater. Lett. 2005, 59, 1422-1425. [CrossRef]

158. Yan, S.J.; Zhou, Z.H.; Zhang, F.; Yang, S.P.; Yang, L.Z.; Yu, X. Bin Effect of anionic PAMAM with amido groups starburst dendrimers on the crystallization of $\mathrm{Ca}_{10}\left(\mathrm{PO}_{4}\right)_{6}(\mathrm{OH})_{2}$ by hydrothermal method. Mater. Chem. Phys. 2006, 99, 164-169. [CrossRef]

159. Zhou, Z.H.; Zhou, P.L.; Yang, S.P.; Yu, X.B.; Yang, L.Z. Controllable synthesis of hydroxyapatite nanocrystals via a dendrimerassisted hydrothermal process. Mater. Res. Bull. 2007, 42, 1611-1618. [CrossRef]

160. Tsiourvas, D.; Tsetsekou, A.; Kammenou, M.I.; Boukos, N. Controlling the formation of hydroxyapatite nanorods with dendrimers. J. Am. Ceram. Soc. 2011, 94, 2023-2029. [CrossRef]

161. Donners, J.J.J.M.; Nolte, R.J.M.; Sommerdijk, N.A.J.M. Dendrimer-based hydroxyapatite composites with remarkable materials properties. Adv. Mater. 2003, 15, 313-316. [CrossRef]

162. Cahill, B.P.; Papastavrou, G.; Koper, G.J.M.; Borkovec, M. Adsorption of poly(amido amine) (PAMAM) dendrimers on silica: Importance of electrostatic three-body attraction. Langmuir 2008, 24, 465-473. [CrossRef]

163. Longtin, R.; Maroni, P.; Borkovec, M. Transition from completely reversible to irreversible adsorption of poly(amido amine) dendrimers on silica. Langmuir 2009, 25, 2928-2934. [CrossRef]

164. Kresge, C.T.; Leonowicz, M.E.; Roth, W.J.; Vartuli, J.C.; Beck, J.S. Ordered mesoporous molecular sieves synthesized by a liquid-crystal template mechanism. Nature 1992, 359, 710-712. [CrossRef]

165. Kruk, M.; Jaroniec, M. Relations between pore structure parameters and their implications for characterization of MCM-41 using gas adsorption and x-ray diffraction. Chem. Mater. 1999, 11, 492-500. [CrossRef]

166. Arkas, M. Hybrid organoceramics deriving from dendritic polymers, methods of preparation, optimization techniques and prospected applications. In Recent Advances in Ceramic Materials Research (Materials Science and Technologies); Nova Science Publishers: Hauppauge, NY, USA, 2013; pp. 1-30, ISBN 9781624177293.

167. Arkas, M. Hybrid Organic/Inorganic Materials Based on Functionalized Dendritic Polymers: Methods of Preparation, Applications and Future Prospects. J. Mater. Sci. Eng. 2012, 1, 1000e103. [CrossRef]

168. Sooklal, K.; Hanus, L.H.; Ploehn, H.J.; Murphy, C.J. A Blue-Emitting CdS/Dendrimer Nanocomposite. Adv. Mater. 1998, 10, 1083-1087. [CrossRef]

169. Garcia, M.E.; Baker, L.A.; Crooks, R.M. Preparation and characterization of dendrimer-gold colloid nanocomposites. Anal. Chem. 1999, 71, 256-258. [CrossRef] [PubMed]

170. Manoth, M.; Manzoor, K.; Patra, M.K.; Pandey, P.; Vadera, S.R.; Kumar, N. Dendrigraft polymer-based synthesis of silver nanoparticles showing bright blue fluorescence. Mater. Res. Bull. 2009, 44, 714-717. [CrossRef]

171. Karakhanov, E.; Maximov, A.; Zolotukhina, A.; Mamadli, A.; Vutolkina, A.; Ivanov, A. Dendrimer-stabilized Ru nanoparticles immobilized in organo-silica materials for hydrogenation of phenols. Catalysts 2017, 7, 86. [CrossRef]

172. Tsiourvas, D.; Papavasiliou, A.; Deze, E.G.; Papageorgiou, S.K.; Katsaros, F.K.; Romanos, G.E.; Poulakis, E.; Philippopoulos, C.J.; Xin, Q.; Cool, P. A green route to copper loaded silica nanoparticles using hyperbranched poly(Ethylene imine) as a biomimetic template: Application in heterogeneous catalysis. Catalysts 2017, 7, 390. [CrossRef]

173. Kitsou, I.; Arkas, M.; Tsetsekou, A. Synthesis and characterization of ceria-coated silica nanospheres: Their application in heterogeneous catalysis of organic pollutants. SN Appl. Sci. 2019, 1. [CrossRef]

174. Gemeinhart, R.A.; Luo, D.; Saltzman, W.M. Cellular fate of a modular DNA delivery system mediated by silica nanoparticles. Biotechnol. Prog. 2005, 21, 532-537. [CrossRef]

175. Radu, D.R.; Lai, C.Y.; Jeftinija, K.; Rowe, E.W.; Jeftinija, S.; Lin, V.S.Y. A polyamidoamine dendrimer-capped mesoporous silica nanosphere-based gene transfection reagent. J. Am. Chem. Soc. 2004, 126, 13216-13217. [CrossRef]

176. Zang, S.; Chang, S.; Shahzad, M.B.; Sun, X.; Jiang, X.; Yang, H. Ceramics-based Drug Delivery System: A Review and Outlook. Rev. Adv. Mater. Sci. 2019, 58, 82-97. [CrossRef]

177. Janaszewska, A.; Lazniewska, J.; Trzepiński, P.; Marcinkowska, M.; Klajnert-Maculewicz, B. Cytotoxicity of dendrimers. Biomolecules 2019, 9, 330. [CrossRef] [PubMed]

178. Patri, A.K.; Majoros, I.J.; Baker, J.R. Dendritic polymer macromolecular carriers for drug delivery. Curr. Opin. Chem. Biol. 2002, 6, 466-471. [CrossRef]

179. Yousefi, M.; Narmani, A.; Jafari, S.M. Dendrimers as efficient nanocarriers for the protection and delivery of bioactive phytochemicals. Adv. Colloid Interface Sci. 2020, 278. [CrossRef] [PubMed] 